\title{
Interest Rates in Trade Credit Markets
}

\author{
Klênio Barbosa \\ Humberto Moreira \\ Walter Novaes \\ Banco BBM \\ EPGE - FGV \\ PUC-Rio \\ klenio@econ.puc-rio.br \\ humberto@fgv.br \\ novaes@econ.puc-rio.br \\ February 10, 2004
}




\begin{abstract}
There is evidence that suppliers have private information about their customers' credit risk. Yet, interest rates in trade credit markets are usually industry-not-firm specific. Why? If the demand for intermediate products is inelastic, suppliers should raise interest rates until they reach their customers' outside option, which, by definition, cannot reflect information that is privy to suppliers. In contrast, a highly elastic demand induces suppliers with monopoly power to waive interest, making private information once more irrelevant to the trade-credit rate. By characterizing these two equilibria, we obtain implications on when trade-credit rates shouldn't vary with private information held by suppliers.
\end{abstract}

JEL: G30, G32

Key Words: Trade Credit; Invariance of Interest Rates. 


\section{Introduction}

Trade credit is one of the most important sources of short-term external financing for firms in the G7 countries (Canada, France, Germany, Italy, Japan, U.K., and the U.S.). ${ }^{1}$ Smith (1987), Mian and Smith (1992) and Biais and Gollier (1997) argue that such prominence is due to an informational advantage: The sales effort of suppliers makes it easier for them to assess their customers' credit risk. Accordingly, Petersen and Rajan (1997) show that, vis-à-vis banks, suppliers extend more credit to firms with current losses and positive growth of sales; a finding that they interpret as evidence that suppliers have comparative advantage in identifying firms with growth potential.

Yet, a supplier's informational advantage is, at first glance, difficult to reconcile with a standard practice in the trade credit markets. Ng, Smith and Smith (1999) and Petersen and Rajan (1994) show that the terms of trade credit in the U.S. are industry-not-firm specific. In particular, a common term of trade credit charges an effective interest rate of 44 percent a year by combining a 30 day maturity with a two percent discount for early payment within 10 days of the invoice (2-10 net 30 loans). But if suppliers are informed lenders, why don't they charge interest rates that reflect variations in the borrowers' risk?

This paper explains when and why interest rates in the trade credit markets do not internalize private information held by suppliers. In a nutshell, suppliers should raise trade-credit rates until they reach their customers' outside option, if the demand for the suppliers' goods is inelastic with respect to the financing costs. By definition, this outside option - e.g., the interest rate available in banking loans - cannot reflect information that is privy to suppliers. In contrast, a sufficiently elastic demand induces suppliers with monopoly power to waive interest, making their private information once more irrelevant to the equilibrium trade-credit rate. Trade credit rates do not vary with the suppliers' private information, therefore, when the demand is inelastic or if suppliers with monopoly power face a demand that is sufficiently elastic with respect to interest rates.

To understand the main ideas of the paper, consider an industry whose firms require financing to purchase inputs from their suppliers. In a fraction $f$ of these firms - the safe firms - the investment in the input will be paid back with probability one. In the remaining firms, fraction

\footnotetext{
${ }^{1}$ See, for example, Rajan and Zingales (1995).
} 
$1-f$, the investment in the input may fail. We call these latter firms risky.

To finance the purchase of inputs, firms can borrow from banks or ask for trade credit. As such, we consider firms that, albeit possibly risky, are not credit constrained. In the model, banks act competitively (i.e., interest rates imply that the expected return on a loan equals the cost of funds), but they cannot distinguish between safe and risky firms. Hence, banks charge the same interest rate $r_{B}$ to all firms in the industry.

In contrast to the banks, suppliers know whether their customers are safe or risky. Thanks to this informational advantage, a supplier may offer interest rates that vary with the firm's type. Competition with banks constrains the suppliers' choices of interest rate, though. In particular, suppliers cannot extend trade credit at an interest rate that is higher than the customer's outside option, which, in our model, is the banking rate $r_{B}$.

To be sure, competition with banks doesn't prevent suppliers from extending credit at low interest rates. Is it in the suppliers' interest to undercut banks? This won't be the case if the demand for the inputs is inelastic with respect to the financing cost. Intuitively, an inelastic demand induces suppliers to, regardless of the customer's creditworthiness, raise interest to the banking rate, which is as high as a trade credit rate can be. An inelastic demand thus gives us a natural candidate for an equilibrium trade credit rate that does not vary with suppliers' private information: the banking rate $r_{B}$. One problem remains for this candidate to be legitimate, though. Informed suppliers may be unwilling to lend to risky firms at an interest rate that is set by uninformed banks that fiercely compete with each other.

As it turns out, there is at least one good reason for suppliers to lend to risky firms at the banking rate. Frank and Maksimovic (1998) argue that suppliers are more efficient than banks in salvaging value from assets of financially distressed firms. If so, suppliers get a higher return than banks when a borrower becomes financially distressed; an advantage that may make it profitable for suppliers to extend credit to risky firms at the banking rate.

What happens if the demand for inputs is inelastic but suppliers are not more efficient than banks in lending to risky firms? The equilibrium at the banking rate breaks down. Petersen and Rajan (1997) show that suppliers extend less credit in industries that keep a high fraction of finished goods in inventory; a finding that they interpret as evidence that it is easier for suppliers to transform repossessed inputs (rather than finished goods) into liquid assets. Accordingly, our 
model predicts that suppliers are more likely to offer standardized rates in industries that keep a low fraction of finished goods in the inventory. This implication will not hold, for instance, if the observed rigidity of trade credit rates in the U.S. reflects suppliers' ability to use the price of their products to adjust for the riskiness of their customers.

Our model builds on two recent papers: Biais and Gollier (1997) and Burkart and Ellingsen (2002). These articles explain why suppliers lend to firms that have exhausted their debt capacity with banks. In Biais and Gollier, suppliers can identify firms whose credit risks are overestimated by banks. Knowing that a firm's credit line is unduly low, suppliers are willing to extend trade credit. In Burkart and Ellingsen, financially constrained firms have access to trade credit because it implies a lower risk of misuse of corporate funds than banking loans. In Biais and Gollier's and Burkart and Ellingsen's models, the optimal trade-credit rate varies with the suppliers' information.

Brennan, Maksimovic and Zechner (1988) is another related work. In this paper, a monopolist sells products to safe and risky customers, discriminating the demand by offering trade credit to the risky customers at a subsidized interest rate. As in Biais and Gollier (1997) and Burkart and Ellingsen (2002), the optimal trade-credit rate in Brennan, Maksimovic and Zechner would vary with the suppliers' private information, had there been trade credit to customers in different classes of risk.

As in Brennan, Maksimovic and Zechner (1988), a sufficiently elastic demand for inputs makes low financing costs so important to sales that, in our model, it dissuades the suppliers from raising the trade-credit rate to their customers' outside option. In fact, we shall demonstrate that suppliers with monopoly power have incentives to waive interest, if the demand for inputs is sufficiently elastic. A second equilibrium in which the trade-credit rate does not internalize the suppliers' private information thus obtains: trade credit at zero interest.

In our model, therefore, interest rates in trade credit markets do not internalize private information held by suppliers, in two instances. If the demand for inputs is inelastic, in which case the trade credit rate matches the customers' outside option, or if the supplier has monopoly power and the demand for inputs is sufficiently elastic, in which case the equilibrium trade credit rate is at zero.

In addition to explaining why trade-credit rates shouldn't vary with private information held 
by suppliers, our model links the invariance of trade-credit rates to whether firms are credit constrained. Since waiving interest attracts all types of firms, there is no reason for the demand for trade credit at zero interest to consist mainly of credit constrained firms. It is easy to see, however, that, at positive trade-credit rates, private information held by suppliers matters when customers are credit constrained. In this case, competition with banks does not constrain the suppliers' choices of trade-credit rates, implying that the optimal terms of trade credit depend on any firm-specific information that suppliers may have: elasticity of demand, probability of default, etc. Another prediction of our model is thus that suppliers are more likely to offer standardized rates to customers that are not credit constrained.

The remainder of the paper is organized as follows. After presenting the model in section 2 , section 3 characterizes the equilibrium in which the trade credit rate does not vary with private information held by suppliers. In section 4 , we discuss the empirical implications and exhibit sufficient conditions for uniqueness of equilibrium. Section 5 then concludes. Proofs of the propositions that are not in the text can be found in the appendix.

\section{The Model}

Consider an economy with two dates, $t=0$ and $t=1$, and an industry with three risk-neutral agents: firms, banks, and a supplier of the firms' inputs. At $t=0$, firms require financing to purchase inputs. Banks are always willing to finance the purchase of inputs at an interest rate that covers the cost of funds. Firms, however, may have a second source of financing: trade credit. With an exogenous probability $x$, the supplier has enough funds to finance its customers. Upon the purchase of inputs at $t=0$, production takes place and firms sell the output at $t=1$. At this time, firms repay the debt and distribute any remaining cash flow to shareholders. Below we describe the agents' technologies and their information structures.

\section{$2.1 \quad$ Firms}

There are two types of firms, safe and risky, which are run by value-maximizing managers who know their firms' types from the onset. The safe firms represent a fraction $f$ of the population and have a deterministic production function. With this safe technology, investing $I$ units of 
the input at $t=0$ obtains $Q(I)$ at $t=1$. We assume that $Q(I)$ is an increasing and strictly concave function, with $Q(0)=0$ and satisfying the following condition: there exist investment levels $\underline{I}$ and $\bar{I}$ such that $Q^{\prime}(\underline{I})>p(1+r) / f$ and $Q^{\prime}(\bar{I})<p$, where $r$ is the riskless interest rate, $f$ is the proportion of safe firms in the industry, and $p$ is the price of the input. These harmless assumptions on the marginal productivity assure that firms buy a positive level of input.

Risky firms are endowed with a stochastic production function. With this technology, purchasing $I$ units of input at $t=0$ yields $\tilde{Q}(I)$ at $t=1$, where:

$$
\tilde{Q}(I)=\left\{\begin{array}{l}
Q(I), \text { with probability } \pi \\
p \delta I, \text { with probability } 1-\pi, \text { and } \delta \epsilon(0,1) .
\end{array}\right.
$$

Note that, with probability $\pi$, the risky technology is as profitable as the safe technology. But, with probability $1-\pi$, the risky technology gets into trouble; the fraction $1-\delta$ of purchased inputs is lost and the only return on the investment is an amount $\delta I$ of inputs that remained unused, yielding a residual value $p \delta I$. We assume that both $Q(I)$ and $\tilde{Q}(I)$ are verifiable. As such, firms can write debt contracts that are contingent on the realization of outputs.

\subsection{Banks}

In the model, banks can neither distinguish between firms of different types nor observe the terms of trade credit. Banks know only the proportion of safe and risky firms, and the amount of inputs $I$ that firms purchase. Since banks operate in a competitive market, they will set an interest rate, $r_{B}$, that yields their opportunity cost. Given risk neutrality, this opportunity cost is the riskless interest rate $r$.

If a risky firm fails, the lender captures the firm's output, $\tilde{Q}(I)$, which is the fraction $\delta$ of the amount $p I$ originally purchased. It is unlikely, nonetheless, that banks can costlessly transform $\delta I$ into liquid assets. In fact, one of the key assumptions of our paper is that banks are not as efficient as suppliers in transforming inputs into liquid assets. To emphasize this difference between banks and suppliers, and to facilitate the analysis, we assume that neither the banks nor the firms can rescue the unused inputs, $\delta I$, if the technology fails. 


\subsection{The supplier}

To focus the analysis on the trade credit market, we follow Brennan, Maksimovic and Zechner (1988) and assume that suppliers cannot use the price of the input to discriminate the demand. As Petersen and Rajan (1997) point out, this hypothesis can be justified by anti-trust laws.

Yet, we do not want to restrict the attention to industries in which a supplier has monopoly power in the market for input. Despite assuming that each firm buys inputs from a single supplier, the input market may be contestable, that is, the potential entry of alternative suppliers may drive input prices down to marginal cost. Hence, we assume that the supplier faces a constant marginal cost $c$ and an exogenous price $p$ of the input. The mark-up, $\frac{p}{c}$, measures the degree of monopoly power in the market for input. For $\frac{p}{c}=1$, the market for inputs is competitive, while $\frac{p}{c}>1$ implies that the supplier enjoys some monopoly power. In this latter case, the supplier faces a two-stage problem; choosing the optimal trade-credit rate for any given input price in the first stage, and then looking for the optimal input price in the second stage. For the purpose of our work, we can restrict attention to the first stage problem, characterizing the optimal trade-credit rate as a function of the mark-up $\frac{p}{c}$.

A common view in the trade-credit literature is that suppliers have comparative advantage over banks in financing purchases of inputs. Biais and Gollier (1997) argue, for instance, that an ongoing sales effort makes it easier for suppliers to evaluate their customers' credit risk; an argument that Petersen and Rajan (1997) find evidence for. Accordingly, we assume that, unlike the banks, the supplier knows whether a firm is risky or safe.

Ability to evaluate risk of credit is not the only reason for the existence of trade credit, though. Petersen and Rajan (1997) also find evidence that suppliers are more efficient than banks in transforming collateral into liquid assets. To model this advantage, we follow Frank and Maksimovic (1998) and assume that, unlike the banks, the supplier can costlessly resell inputs that they capture from bankrupted firms. Hence, when a risky investment of $I$ units of input fails, the supplier captures the unused inputs, $\delta I$, assuring some return on their trade credit. We assume, however, that the supplier loses when a risky customer is bankrupted. That

is, the present value of the rescued inputs $\frac{p \delta I}{1+r}$ is lower than the suppliers' cost of producing the input, $c I$, which implies that $\frac{p}{c}<\frac{1+r}{\delta}$; an inequality that is trivially satisfied if the input market is competitive. 
But, as Mian and Smith (1992) show, some suppliers do not have access to funds that can be used to provide trade credit. We model this potential constraint as follows. With a probability $x$ in the interval $(0,1)$, our supplier has access to funds at the same cost of banks, $r$. In this event, the supplier can extend trade credit. With probability $1-x$, however, the supplier has no access to funds, ruling out trade credit. Firms will then have to secure bank loans to purchase inputs. The supplier's stochastic cost of funds assures an active role for banking credit, despite the supplier's potential advantage as a lender.

\subsection{The game in the extensive form}

Figure 1 describes the extensive form of the game. Nature acts first, determining at date $t=-1$ the type of the firm (safe or risky) and whether the supplier can provide trade credit. At $t=0$, the supplier and the firms learn the firms' types and whether trade credit is available. If the supplier cannot extend trade credit, an event with probability $1-x$, firms borrow from banks before purchasing $I_{B}$ from the supplier. If, instead, trade credit is available, the banks and the supplier make simultaneous offers to finance purchases of inputs. Since banks do not know the firm's type, they offer the same interest rate $r_{B}$ to both types of firms, while the informed supplier may tailor the interest rate to the firm's type, offering $r_{T}^{R}$ to risky firms and $r_{T}^{S}$ to safe firms. These interest rates determine firms' returns on the purchase of inputs, inducing risky firms to invest $I_{T}^{R}$ and safe firms to invest $I_{T}^{S}$.

At time $t=1$, cash flows are generated according to the production functions $Q(I)$ and $\tilde{Q}(I)$. And firms pay back their loans whenever possible. Shareholders then capture any cash flow left after the debt is paid.

The game has two types of equilibria. In the first one, the supplier lends to at most one type of firm. In the second type of equilibrium, suppliers lend to both types of firms, whenever possible. The first type of equilibrium is not interesting for the purposes of our work. If borrowers are all in the same class of risk, there is no scope for the supplier to vary the trade-credit rate with the customers' creditworthiness. As such, our focus in on the equilibrium in which, whenever possible, the supplier lends to both types. After characterizing this equilibrium in section 3 , we exhibit conditions for it to be unique in section 4 . 


\section{Equilibrium with Invariance of Interest Rates}

\subsection{Banking credit}

In the equilibrium that we look for, the supplier extends trade credit to both types of firms, whenever possible. When trade credit is not available, an event with probability $1-x$, firms finance purchases of inputs by borrowing from banks. Let us then start our analysis by deriving the demand for inputs of a safe firm that borrows from banks at an interest rate $r_{B}$.

By assumption, safe firms can always repay loans that are used to finance inputs. ${ }^{2}$ As a result, a safe firm's optimal investment in inputs solves:

$$
\max _{I} \frac{Q(I)-\left(1+r_{B}\right) p I}{(1+r)} .
$$

Program (1) looks for the investment that maximizes the present value of a safe firm's profit. By investing $p I$ at $t=0$, a safe firm obtains $Q(I)$ at $t=1$ with probability one, paying $\left(1+r_{B}\right) p I$ in principal plus interest to the bank (also at $t=1$ ). Since the investment of a safe firm is riskless, we discount its payoff at the riskless interest rate $r$. Given the interest rate $r_{B}$, the first order condition, which is also sufficient, yields the demand for inputs of the safe firm, $I_{B}^{S}\left(r_{B}\right)$, by setting the marginal productivity of investing in the input equal to the cost of financing:

$$
Q^{\prime}\left(I_{B}^{S}\right)=\left(1+r_{B}\right) p
$$

Consider now a risky firm that borrows $p I$ to purchase inputs. With probability $\pi$, the investment will yield the same return $Q(I)$ of the safe firms. With probability $1-\pi$, however, the investment will fail, leaving only $\delta I$ units of inputs at $t=1$. Regardless of the lender's ability to transform the residual inputs into liquid assets, a failure of the risky technology implies that the firm loses all rights on the residual inputs. Given the assumption of risk neutrality, the demand for inputs of a risky firm, $I_{B}^{R}\left(r_{B}\right)$, maximizes the present value of the expected payoffs, using the riskless interest rate as the discount rate, that is,

\footnotetext{
${ }^{2}$ For any finite interest rate, our assumptions on the marginal productivity of investment (see section 2.1) assure that a small purchase of inputs will more than offset the costs of servicing the debt, leaving a positive profit for the safe firm. Hence, an optimal choice of inputs must imply a positive profit as well. In the absence of uncertainty, a positive profit implies that any debt will be repaid with probability one.
} 


$$
\max _{I} \frac{\pi\left[Q(I)-\left(1+r_{B}\right) p I\right]}{(1+r)} .
$$

Like the safe firms, a risky firm's demand for inputs sets the marginal productivity of investment equal to the cost of financing, that is, $Q^{\prime}\left(I_{B}^{R}\right)=\left(1+r_{B}\right) p$. It then follows that the demand schedules of safe and risky firms are equal, that is, $I_{B}^{S}=I_{B}^{R}=I_{B}$. Indeed, had the demand for loans varied across firms of different types, banks would have been able to infer the type of a firm that requests a loan. Banks and suppliers would then end up with the same information structure, and our model would not be fit to explain why interest rates in the trade credit markets do not seem to reflect suppliers' private information about their customers.

Of course, a request of a bank loan may convey information even if safe and risky firms have identical demands for inputs. For instance, in an equilibrium in which the supplier finances only safe firms, banks should expect that most of their loans go to risky firms. (Banks should not expect all firms to be risky because lack of trade credit might lead safe firms to look for banking credit.) In the equilibrium that we look for, though, the supplier finances both types of firms, whenever possible. Thus, banks know that lack of funds for trade credit is the only reason for firms asking for bank loans. Accordingly, requests of loans do not convey information, and banks do not update their priors about firms' types.

Provided that requests for loans do not convey information, we can easily derive the equilibrium interest rate $r_{B}$. Since the technologies of both types of firms are common knowledge, the banks know that safe firms will pay principal plus interest with probability one, while risky firms will honor the debt contract with probability $\pi$. (Risky firms do not pay anything with probability $1-\pi$.) Therefore, the banks will collect principal plus interest at $t=1$ if the firm is safe, probability $f$, or if the firm is risky but the technology does not fail, probability $\pi(1-f)$. In other words, the probability that a borrower pays a bank at $t=1$ is $f+\pi(1-f)$. And the expected return of a bank that lends at a rate $r_{B}$ is $\left(1+r_{B}\right)(f+\pi(1-f))$.

Competition among banks drives the expected returns on banking loans to their opportunity cost, which, under the assumption of risk neutrality, is the riskless interest rate $r$. As such, the interest rate that assures banks their opportunity cost is

$$
r_{B}=\frac{1+r}{f+\pi(1-f)}-1 .
$$


Having characterized the equilibrium banking rate and the demand for inputs of firms that borrow from banks, our next task is to introduce trade credit. Two questions then naturally arise. Is it optimal for the supplier to finance purchases of inputs? What is the optimal interest rate in the trade credit market? Answering these questions requires solving for the investment decision of a firm that has the option of using trade credit to finance purchases of inputs.

As it turns out, trade credit does not fundamentally change firms' investment decisions. Whether a firm borrows from banks or from the supplier, all that matters is the cost of financing. It then follows that the investment decisions of safe and risk firms are still characterized by, respectively, programs (1) and (3), once we substitute the minimum cost of financing for the banking rate. Thus, for both types of firms, the demand for inputs, $I$, is implicitly defined by the equality of the marginal productivity of investment and the cost of financing. Formally,

$$
Q^{\prime}(I(s))=(1+s) p,
$$

where $s$ is the lowest between the banking rate and the trade credit rate.

Equation (5) determines the shape of the demand for inputs. A straightforward application of the implicit function theorem shows that the demand for inputs decreases with the cost of financing. Furthermore, the demand is strictly concave if $Q^{\prime \prime \prime}(I)<0 .{ }^{3}$ Equipped with the demand for inputs, the next two sections characterize the supplier's optimal strategies, starting with the optimal terms of trade credit of a supplier that faces a safe customer.

\subsection{The supply of trade credit to safe firms}

In our model, a sale of inputs is not necessarily linked to trade credit. Firms can borrow from banks to finance purchases of inputs and, rather than extending trade credit, suppliers can let banks finance the firms. These outside options impose restrictions on the optimal terms of trade credit. For instance, no safe firm will accept terms of trade credit that ask for an interest rate that is larger than the banking rate $r_{B}$. As such, a first restriction for the optimal trade-credit

\footnotetext{
${ }^{3}$ To show that $I(\cdot)$ is decreasing and concave (under $Q^{\prime \prime \prime}(\cdot)<0$ ) on the cost of financing, apply the implicit function to $Q^{\prime}(I)=(1+s) p$ to obtain $I^{\prime}=\frac{p}{Q^{\prime \prime}(I)}$, which is negative because, by assumption, $Q^{\prime \prime}(I)<0$. Assuming $Q^{\prime \prime \prime}<0$ and differentiating a second time yields $I^{\prime \prime}=-\frac{Q^{\prime \prime \prime}(I)}{Q^{\prime \prime}(I)^{2}} p I^{\prime}<0$.
} 
rate is $r_{T}^{S} \leq r_{B} \cdot{ }^{4}$

In turn, the supplier is not obliged to extend trade credit to sell its products. Banks can finance purchases of inputs! To see what type of restriction this outside option yields, consider first the supplier's discounted profits, $\Phi_{T}^{S}\left(r_{T}^{S}\right)$, for a given trade credit rate $r_{T}^{S}$ :

$$
\Phi_{T}^{S}\left(r_{T}^{S}\right)=p\left(\frac{1+r_{T}^{S}}{1+r}\right) I\left(r_{T}^{S}\right)-c I\left(r_{T}^{S}\right)
$$

At a trade-credit rate $r_{T}^{S}$, the demand for inputs is $I\left(r_{T}^{S}\right)$, implying that the supplier will finance $p I\left(r_{T}^{S}\right)$ at time $t=0$ and will collect $p\left(1+r_{T}^{S}\right) I\left(r_{T}^{S}\right)$ in principal plus interest at $t=1$, when the trade credit is due. Discounting this riskless cash inflow to time $t=0$ and subtracting the supplier's cost of production yield equation (6) as the discounted profit.

Suppose now that, rather than extending trade credit, the supplier lets banks finance safe firms at an interest rate $r_{B}$. The demand for inputs of the safe firm will then be $I\left(r_{B}\right)$, generating a profit for the supplier on the amount of $(p-c) I\left(r_{B}\right)$. The supplier's outside option of letting banks finance safe firms then requires that profits with trade credit, $\Phi_{T}^{S}\left(r_{T}^{S}\right)$, are bigger than or equal to $(p-c) I\left(r_{B}\right)$. The supplier's problem is thus

$$
\begin{gathered}
\max _{r_{T}^{S}} p\left(\frac{1+r_{T}^{S}}{1+r}\right) I\left(r_{T}^{S}\right)-c I\left(r_{T}^{S}\right) \\
\text { subject to } 0 \leq r_{T}^{S} \leq r_{B}, \\
p\left(\frac{1+r_{T}^{S}}{1+r}\right) I\left(r_{T}^{S}\right)-c I\left(r_{T}^{S}\right) \geqslant(p-c) I\left(r_{B}\right) .
\end{gathered}
$$

The objective function of Program (7) is the discounted profit of a supplier who extends trade credit to a safe firm. The constraint (8) rules out interest rates that are larger than the banking rate and imposes a lower bound that prevents negative interest rates. The rationale for this lower bound is as follows. A negative trade-credit rate is observably equivalent to a combination of a zero interest and a discount in the price of the input. Hence, ruling out negative trade-credit rates

\footnotetext{
${ }^{4} \mathrm{~A}$ supplier with monopoly power may fetch an interest rate higher than $r_{B}$ by denying inputs to firms that do not use trade credit. The analysis in the paper, therefore, ignores distortions in the trade credit markets that are driven by these types of bundling strategies.
} 
amounts to restricting attention to testable implications on the trade-credit rates. Finally, the inequality (9) assures that profits with trade credit outweigh profits conditioned on letting banks finance the safe firm, which is the supplier's outside option. If this condition is not satisfied, it is optimal for the supplier not to extend trade credit to the safe firm.

As we showed in section $3.1, Q^{\prime \prime \prime}()<$.0 is a sufficient condition for the demand for inputs to be strictly concave. Under this assumption and defining the interest-elasticity of demand as $\epsilon\left(r_{T}^{S}\right)=-\frac{\left(1+r_{T}^{S}\right) I^{\prime}\left(r_{T}^{S}\right)}{I\left(r_{T}^{S}\right)}$, Proposition 1 characterizes the optimal trade-credit rate with a safe firm.

Proposition 1 - Assume that the investment function is strictly concave on the interest rate. Thus, it is optimal for the supplier to extend trade credit to safe firms, and the optimal trade credit-rate, $r_{T}^{* S}$, is

$r_{T}^{* S}=\left\{\begin{array}{l}r_{B}, \text { if } \epsilon\left(r_{B}\right) \leq \frac{p \frac{1+r_{B}}{1+r}}{p \frac{1+r_{B}}{1+r}-c} \equiv \bar{\epsilon}^{S}\left(r_{B}\right) \\ 0, \text { if } \frac{p}{c}>1+r \text { and } \epsilon^{D}(0) \geq \frac{\frac{p}{1+r}}{\frac{p}{1+r}-c} \equiv \bar{\epsilon}^{S}(0) \\ \widehat{r}_{T}^{S} \in\left(0, r_{B}\right), \text { if } \epsilon\left(r_{B}\right)>\bar{\epsilon}^{S}\left(r_{B}\right) \text { and either } \epsilon(0)<\bar{\epsilon}^{S}(0) \text { or } \frac{p}{c} \leq 1+r .\end{array}\right.$

To get some intuition for Proposition 1, let us compare the supplier's profit with and without trade credit. Without trade credit, banks will finance the safe firm at an interest rate $r_{B}$, implying that the supplier will sell - for cash $-I\left(r_{B}\right)$ units of the input at a profit of $(p-c) I\left(r_{B}\right)$. In turn, equation (6) shows the supplier's discounted profit with trade credit, which can be rewritten as $\Phi_{T}^{S}\left(r_{T}^{S}\right)=(p-c) I\left(r_{T}^{S}\right)+\left(\frac{r_{T}^{S}-r}{1+r}\right) p I\left(r_{T}^{S}\right)$. This equation decomposes the discounted profits in two parts: the operational profits, $(p-c) I\left(r_{T}^{S}\right)$, and the financial profits, $\left(\frac{r_{T}^{S}-r}{1+r}\right) p I\left(r_{T}^{S}\right)$. By extending trade credit at the banking rate $r_{B}$, the operational profit matches the total profits without trade credit, $(p-c) I\left(r_{B}\right)$, and, in addition, the supplier gets a financial profit of $\left(\frac{r_{B}-r}{1+r}\right) p I\left(r_{B}\right)>0$. Hence, it is always optimal for the supplier to extend trade credit to safe firms.

The banking rate is not necessarily the optimal trade-credit rate, though. On the one hand, a large trade-credit rate increases financial profits per unit of trade credit, $\frac{r_{B}-r}{1+r}$. On the other hand, it reduces the demand for inputs, at least partially offsetting the benefits of a large financial margin. A trade off on the choice of the trade-credit rate thus exists. Analogously to the analysis of monopoly pricing, the proof of Proposition 1 shows that there is a cut-off for the elasticity of 
demand at $r_{B}, \frac{p \frac{1+r_{B}}{1+r}}{p \frac{1+r_{B}}{1+r}-c}$, below which the gains of a large margin outweigh the loss of demand, making it optimal for the supplier to increase the trade-credit rate to the upper bound $r_{B}$.

What happens if the elasticity of demand does not satisfy $\epsilon\left(r_{B}\right) \leq \frac{p \frac{1+r_{B}}{1+r}}{p \frac{1+r_{B}}{1+r}-c}$ ? Then the optimal trade rate is lower than $r_{B}$, because the gains from an increased demand for inputs more than offset the loss of the financial margin. The mark-up of the supplier and the elasticity of demand determine how low the optimal trade-credit rate will go. Waiving interest is optimal if the markup is large enough to assure profits at a zero interest, $\frac{p}{c}>1+r$, and if, despite the zero-interest, the demand remains sufficiently elastic, $\epsilon(0) \geq \frac{\frac{p}{1+r}}{\frac{p}{1+r}-c}$. If either of these two conditions does not hold, then the optimal trade-credit rate makes marginal profits equal to zero, lying in the open interval $\left(0, r_{B}\right)$.

In section 3.4, we will use Proposition 1 to exhibit conditions that assure that the supplier chooses the same interest rate for safe and risky firms. But first we must derive the supply of trade credit to risky firms.

\subsection{The supply of trade credit to risky firms}

Let us now move to the risky firms. In our model, risky firms have the option of borrowing from banks at the interest rate $r_{B}$. At such interest rate, the expected return of lending to risky firms does not cover the banks' cost of funds; banks lend to risky firms at $r_{B}$ because they do not know the firm's type. The banks' inability to distinguish between risky and safe firms may have repercussions in the trade credit markets. In particular, the banking system works as an outside option for the risky firms, preventing the supplier from extending trade credit at an interest rate larger than $r_{B}$. But why should then a supplier lend to risky firms at an interest rate that banks would deny credit had they known the firm's type?

Suppliers have at least two reasons for extending trade credit at an interest rate $r_{T}^{R} \leq r_{B}$. First, lending to risky firms at $r_{B}$ may impose an expected loss to banks and yet assure an expected profit to suppliers if their comparative advantage over banks in transforming collateral into liquid assets, $\delta$, is large enough. Second, as Schwartz and Whitcomb (1997) and Brennan, Maksimovic and Zechner (1998) point out, suppliers with monopoly power may be willing to offer a subsidized rate to boost profitable sales. Accordingly, one would expect that if either the supplier's comparative advantage in default, $\delta$, or its markup, $\frac{p}{c}$, is large enough, then extending 
trade credit should outweigh the supplier's outside option of letting banks finance the risky firm, that is,

$$
\pi\left[p\left(\frac{1+r_{T}^{R}}{1+r}\right)-c\right] I\left(r_{T}^{R}\right)+(1-\pi)\left[\frac{\delta p}{(1+r)}-c\right] I\left(r_{T}^{R}\right) \geq(p-c) I\left(r_{B}\right)
$$

The left-hand side of the inequality (10) is the supplier's discounted profit conditioned on extending trade credit at an interest rate $r_{T}^{R}$. With probability $\pi$, the risky firm succeeds, paying principal plus interest, $p\left(1+r_{T}^{R}\right) I\left(r_{T}^{R}\right)$, at time $t=1$. With probability $1-\pi$, the risky firm fails and all the supplier can do is to rescue the unused inputs and resell them for $\delta p I\left(r_{T}^{R}\right)$. From the risky-neutrality assumption, the expected cash flow $\pi p\left(1+r_{T}^{R}\right) I\left(r_{T}^{R}\right)+\delta p I\left(r_{T}^{R}\right)$ is discounted at the riskless interest rate to $t=0$. The discounted profit then obtains once we subtract the cost of producing the input. Condition (10) requires that this discounted profit be larger than the supplier's profit without trade credit, which is cashed at $t=0$ and amounts to $(p-c) I\left(r_{B}\right) .^{5}$

Writing condition (10) as a lower bound on the supplier's advantage in default yields

$$
\delta \geq \frac{c}{p}\left(\frac{1+r}{1-\pi}\right)\left(\frac{I\left(r_{T}^{R}\right)-I\left(r_{B}\right)}{I\left(r_{T}^{R}\right)}\right)+\frac{(1+r) I\left(r_{B}\right)-\pi\left(1+r_{T}^{R}\right) I\left(r_{T}^{R}\right)}{(1-\pi) I\left(r_{T}^{R}\right)} \equiv \bar{\delta}\left(r_{T}^{R}\right) .
$$

Extending trade credit to a risky firm at an interest rate $r_{T}^{R}$ can thus be optimal only if the supplier's advantage in rescuing assets of bankrupted firms, $\delta$, is larger than or equal to a cut-off, $\bar{\delta}\left(r_{T}^{R}\right)$, that assures that profits match the supplier's outside option, $(p-c) I\left(r_{B}\right)$. As section 4 will show, this necessary condition yields testable implications of our model. Accordingly, we shall substitute condition (11) for condition (10), writing the supplier's problems as

\footnotetext{
${ }^{5}$ The role of the banking rate as an outside option thus determines the equilibrium level of interest rates in the trade credit markets, even for suppliers that provide all of their customers' financing requirements. Felli and Harris (1996) explore this role of outside options in a model of investment decisions in human capital. They show that an employee's productivity in a rival firm matters, even when an investment in firm-specific human capital reduces the chances that the employee changes jobs.
} 


$$
\begin{gathered}
\max _{r_{T}^{R}} \pi\left[p\left(\frac{1+r_{T}^{R}}{1+r}\right)-c\right] I\left(r_{T}^{R}\right)+(1-\pi)\left[\frac{\delta p}{(1+r)}-c\right] I\left(r_{T}^{R}\right) \\
\text { subject to } 0 \leq r_{T}^{R} \leq r_{B} \\
\delta \geq \bar{\delta}\left(r_{T}^{R}\right) .
\end{gathered}
$$

Proposition 2 characterizes the solution of program (12), showing that the optimal tradecredit rate depends not only on the supplier's advantage in rescuing assets of bankrupted firms, $\delta$, but also on the interest-elasticity of the demand for inputs, $\epsilon\left(r_{T}^{R}\right)$, and the mark-up $\frac{p}{c}$.

Proposition 2 - Assume that the demand for inputs is strictly concave on the interest rate and let $r_{T}^{* R}$ be the trade-credit rate that, conditioned on extending trade credit, maximizes the supplier's discounted profits. Thus, it is optimal for the supplier to extend trade credit to risky firms if and only if $\delta \geq \bar{\delta}\left(r_{T}^{* R}\right)$, in which case $r_{T}^{* R}$ is the optimal trade-credit rate and is characterized by

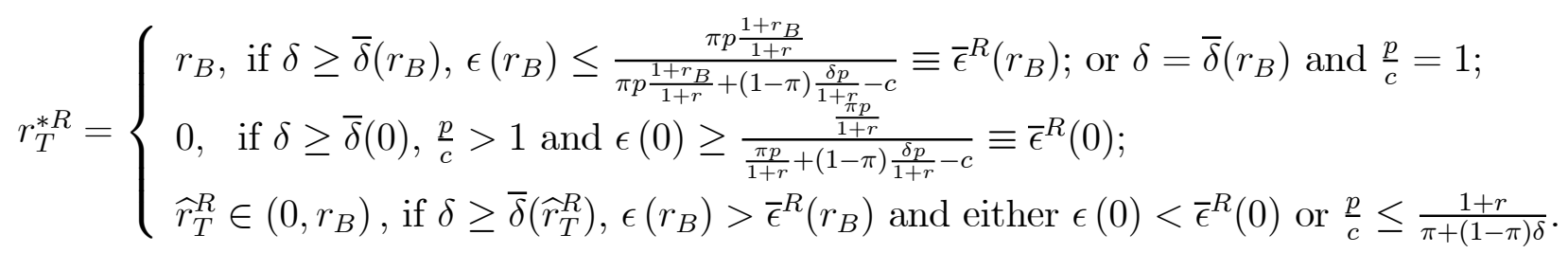

Unlike in the case of a safe firm, Proposition 2 shows that trade credit to risky firms may be optimal and yet the best that the supplier can do is to break even. This will happen if the supplier's advantage in default is just enough to assure the supplier's outside option, $\delta=\bar{\delta}\left(r_{B}\right)$, and, in addition, competition in the market for inputs, $\frac{p}{c}=1$, drives the outside option to zero. In this case, trade credit implies an expected loss for any interest rate lower than $r_{B}$. The banking rate, therefore, maximizes discounted profits - and solves the supplier's problem - regardless of the elasticity of demand.

The trade-off between margin of profits and volume of transactions becomes relevant again, though, if the supplier has monopoly power, $\frac{p}{c}>1$, or if its advantage in default makes trade credit a strictly dominant strategy for the supplier, that is, $\delta>\bar{\delta}\left(r_{B}\right)$. In both cases, extending trade credit to risky firms at the banking rate yields positive profits. And, as in the case of a safe firm, the banking rate is $r_{B}$ is indeed the optimal trade-credit rate if and only if the demand 
for inputs is sufficiently inelastic at $r_{B}$, that is, $\epsilon\left(r_{B}\right) \leq \frac{\pi p \frac{1+r_{B}}{1+r}}{\pi p \frac{1+r_{B}}{1+r}+(1-\pi) \frac{p \delta}{1+r}-c}$. If the demand is not sufficiently inelastic, then it is optimal for the supplier to reduce the trade-credit, and it is optimal to waive interest if and only if the supplier has monopoly power, $\frac{p}{c}>1$, and the demand remains sufficiently at the zero interest rate $\left(\epsilon(0) \geq \frac{\frac{\pi p}{1+r}}{\frac{\pi p}{1+r}+(1-\pi) \frac{\delta p}{1+r}-c}\right){ }^{6}$

Propositions 1 and 2 establish the optimal terms of trade credit to safe and risky firms, giving us all we need for characterizing an equilibrium in which the trade-credit rate does not vary with the firm's type.

\subsection{Characterizing the equilibrium}

An equilibrium in which the trade-credit rate does not vary with the firm's type has two main ingredients. First, the supplier must have incentives to extend trade credit to both types of firms, or else we rule out variations of interest rates across firms from the onset. While the supplier always has incentives to extend trade credit to safe firms, Proposition 2 shows that trade credit to risky firms is optimal if and only if the supplier's advantage in rescuing unused inputs, $\delta$, is larger than a certain cut-off $\bar{\delta}\left(r_{T}^{* R}\right)$. Intuitively, this first restriction limits the cost that a risky firm's default may impose on the supplier.

The second ingredient for an equilibrium with invariant trade-credit rates is standard: there cannot be incentives for the supplier to deviate from the invariant rate, regardless of the firm's type. Accordingly, the equilibrium trade-credit rate must satisfy the first order conditions of problems (7) and (12). Proposition 3, below, shows that this restriction implies that the optimal trade-credit rate with a risky firm is larger than or equal to the optimal rate with a safe firms. More importantly, the proposition shows that these optimal trade-credit rates can be equal only at the banking rate or at zero, which are, therefore, the only candidates for an equilibrium trade-credit rate that does not vary with the firm's type.

Proposition 3 - The optimal trade-credit rate with a risky firm is bigger than or equal to the optimal trade-credit rate with a safe firm, with equality only at the banking rate and at the zerointerest rate. In particular, if it is optimal for the supplier to extend trade credit to risky firms

\footnotetext{
${ }^{6}$ The proof of Proposition 2 shows that, for waiving interest to be optimal, the mark-up must be large enough to assure strictly positive profits at a zero trade-credit rate, that is, $\frac{p}{c}>\frac{1+r}{\pi+(1-\pi) \delta}$. The proof of Proposition 2 also shows, nonetheless, that monopoly power, $\frac{p}{c}>1$, suffices for strictly positive profits if we also require $\delta \geq \bar{\delta}(0)$.
} 
at zero interest, then waiving interest is also optimal with a safe firm. And if it is optimal for the supplier to offer trade credit to safe firms at the banking rate, then either it is not optimal to extend trade credit to risky firms or the banking rate is the optimal trade-credit rate with a risky firm.

The intuition for Proposition 3 is straightforward. Although a high interest rate assures creditors a high margin of financial profits, it reduces the demand for loans, partly offsetting the benefits of a high margin. These incentives for lowering interest rates are at their peak when the borrower is a safe firm. In this case, a reduction in the volume of trade credit accounts for the loss of a sure profit. In contrast, a reduction in the volume of trade credit does not lead to a loss in the states of nature that a risky firm becomes bankrupted. As such, the optimal trade-credit rate with a risky firm is in general larger than the optimal rate with a safe firm. The exceptions are at the banking rate, from which a further increase is not possible because banks provide an outside option for the firms; and at a zero-interest rate, from which a further decrease would imply negative interest rates that are observably equivalent to a zero trade-credit rate with a reduction in the price of input (price discrimination).

Accordingly, let's start looking for an equilibrium in which the supplier extends trade credit to both firms at the banking rate. From Proposition 3, if the banking rate maximizes discounted profits with a safe firm, so it does with a risky firm. In turn, Proposition 1 tells us that a necessary and sufficient condition for the trade-credit rate $r_{B}$ to maximize discounted profits with a safe firm is that the elasticity of demand satisfies $\epsilon\left(r_{B}\right) \leq \frac{p \frac{1+r_{B}}{1+r}}{p \frac{1+r_{B}}{1+r}-c}$. Our task is thus to show that, for admissible parameter values, the supplier's advantage in rescuing assets may be large enough to outweigh profits without trade credit $\left(\delta \geq \bar{\delta}\left(r_{B}\right)\right)$, while assuming that $\epsilon\left(r_{B}\right) \leq \frac{p \frac{1+r_{B}}{1+r}}{p \frac{1+r_{B}}{1+r}-c}$.

The condition on the elasticity has a clear economic content. For the supplier to raise the interest rate as much as possible, the elasticity cannot be too large or else the loss in the volume of transactions will more than offset the benefits of a high financial margin. Moreover, this condition can be subsumed in the shape of the production function, $Q(I)$, without imposing further restrictions on the other parameter values. Hence, the second restriction for the equilibrium, $\delta \geq \bar{\delta}\left(r_{B}\right)$, is actually the key one for assuring existence of equilibrium at the banking rate.

Plugging the baking rate into equation condition (11) yields $\bar{\delta}\left(r_{B}\right)=1-\frac{\pi r_{B}-r}{1-\pi}$, which does 
not depend on the mark-up. ${ }^{7}$ The cut-off $\bar{\delta}\left(r_{B}\right)$ does depend, however, on the banking rate, the probability of default, $\pi$, and the riskless interest rate $r$. Because $\delta$ is the fraction of inputs that the supplier can rescue upon the default of a risky firm, it cannot be larger than one. The question then is whether there are admissible parameter values that allow for $\bar{\delta}\left(r_{B}\right)=1-\frac{\pi r_{B}-r}{1-\pi}<1$. Taking into account that the banking rate is $r_{B}=\frac{1+r}{f+\pi(1-f)}-1$, we can rewrite the restriction on $\delta$ as

$$
\delta \geq \frac{(1+r) f}{f+(1-f) \pi} .
$$

For some $\delta \in(0,1)$ to satisfy the inequality (15) we must have $\frac{(1+r) f}{f+(1-f) \pi}<1$, or equivalently, $\frac{f}{1-f} \leq \frac{\pi}{r}$. In other words, the probability that a risky firm repays the debt, $\pi$, must be high relative to the fraction of safe firms in the industry, $f$.

It then follows that, $\frac{f}{1-f} \leq \frac{\pi}{r}, \delta \geq \frac{(1+r) f}{f+(1-f) \pi}$, and $\epsilon\left(r_{B}\right) \leq \frac{p \frac{1+r_{B}}{1+r}}{p \frac{1+r_{B}}{1+r}-c}$ imply that there is an equilibrium in which the supplier extends trade credit to both types of firms at the banking rate at $r_{B}$. Moreover, this equilibrium is unique, if we restrict attention to equilibria in which the supplier extends trade credit to both types of firms. To see why remember that Propositions 1 shows that $\epsilon\left(r_{B}\right) \leq \frac{p \frac{1+r_{B}}{1+r}}{p \frac{1+r_{B}}{1+r}-c}$ is a sufficient condition for the banking rate $r_{B}$ to be a strict optimal trade-credit rate with a safe firm; a result that, from Proposition 3, extends to trade credit to a risky firm if we add $\delta \geq \frac{(1+r) f}{f+(1-f) \pi}$. We have thus established:

Proposition 4 - Suppose that the demand for inputs is strictly concave and $\frac{f}{1-f} \leq \frac{\pi}{r}$. Thus, there exists an equilibrium in which the supplier finances both types of firms at the banking rate $r_{B}=\frac{1+r}{f+\pi(1-f)}-1$ if and only if the interest-elasticity of the demand for inputs at $r_{B}$ is smaller than or equal to $\frac{p \frac{1+r_{B}}{1+r}}{p \frac{1+r_{B}}{1+r}-c}$ and the fraction of unused inputs that the supplier rescues in case a risk firm fails satisfies $\delta \geq \frac{(1+r) f}{f+(1-f) \pi} \in(0,1)$. Moreover, the equilibrium is unique in the class of equilibria in which the supplier extends trade credit to both firms.

Consider now our second candidate for an equilibrium with invariant rates, that is, trade credit to both types of firms at a zero interest rate. Once again, Proposition 3 is the key to characterize the equilibrium: If it is optimal to extend trade credit to risky firms at zero

\footnotetext{
${ }^{7}$ The intuition for the irrelevance of the mark-up is that, vis-à-vis banks, private information gives some monopoly power to the supplier, making the elasticity of the demand for inputs important for the optimal interest rate even if competition in the market for inputs drives prices down to the marginal cost.
} 
interest, then it is also optimal to offer trade credit to safe firms at zero interest. Accordingly, we simply have to show that there are parameter values that satisfy the conditions in Proposition 2 for zero to be the optimal trade-credit rate with a risky firm, that is, $\delta \geq \bar{\delta}(0), \frac{p}{c}>1$ and $\epsilon(0) \geq \frac{\frac{\pi p}{1+r}}{\frac{\pi p}{1+r}+(1-\pi) \frac{\delta p}{1+r}-c}$.

We can certainly assume that some suppliers enjoy monopoly power, $\frac{p}{c}>1$, and that the elasticity of demand at zero satisfies $\epsilon(0) \geq \frac{\frac{\pi p}{1+r}}{\frac{\pi p}{1+r}+(1-\pi) \frac{\delta p}{1+r}-c}$. Showing that there exists $\delta \in(0,1)$ such that $\delta \geq \bar{\delta}(0)$ is not so obvious, though. Plugging zero into equation condition (11) yields $\bar{\delta}(0)=\frac{c}{p}\left(\frac{1+r}{1-\pi}\right)\left(\frac{I(0)-I\left(r_{B}\right)}{I(0)}\right)+\frac{(1+r) I\left(r_{B}\right)-\pi I(0)}{(1-\pi) I(0)}$. Once more, the cut-off depends on the on the banking rate, $r_{B}$, the probability of default, $\pi$, and the riskless interest rate $r$. Unlike in the equilibrium at the banking rate, though, the cut-off decreases with the mark-up $\frac{p}{c}$. Intuitively, a large mark-up makes it easier for waiving interest to outweigh profits without trade credit. Proposition 5 shows that, for a sufficiently large mark-up, there exist admissible parameter values that make $\bar{\delta}(0)<1$, allowing for some $\delta \in(0,1)$ to satisfy $\delta \geq \bar{\delta}(0)$.

Proposition 5 - Suppose that the investment function is strictly concave on the interest rate and that the mark up, $\frac{p}{c}$, is sufficiently large. Thus, there exists an equilibrium in which the supplier extends trade credit to both types of firms at a zero interest rate if and only if the interest-elasticity of the demand for inputs satisfies $\epsilon(0) \geq \frac{\frac{\pi p}{1+r}}{\frac{\pi p}{1+r}+(1-\pi) \frac{\delta p}{1+r}-c}$ and the fraction of unused inputs that the supplier rescues in case a risk firm fails satisfies $\delta \geq \frac{c}{p}\left(\frac{1+r}{1-\pi}\right)\left(\frac{I(0)-I\left((1+r)(f+(1-f) \pi)^{-1}-1\right)}{I(0)}\right)+$ $\frac{(1+r) I\left((1+r)(f+(1-f) \pi)^{-1}-1\right)-\pi I(0)}{(1-\pi) I(0)} \in(0,1)$. Moreover, the equilibrium is unique in the class of equilibria in which the supplier extends trade credit to both firms.

A quick inspection of Propositions 4 and 5 shows two major differences in the restrictions for the two equilibria at an invariant trade-credit rate. For an equilibrium at the banking rate, all we need is that demand for inputs is sufficiently inelastic. For an equilibrium at the zero interest rate, we need more. The demand must be sufficiently elastic and the supplier must enjoy monopoly power. Propositions 4 and 5 thus suggest that the equilibrium at the banking rate is more pervasive.

Nonetheless, Propositions 4 and 5 also show the two equilibria with invariant trade-credit rates share a common restriction. They both require a minimum level for the supplier's advantage in rescuing assets of bankrupted firms, $\delta$. Economic intuition suggests, though, that a large $\delta$ might 
not be necessary if the mark-up and the elasticity of demand are so large that a reduction in the cost of financing to zero significantly enhance expected profits. Proposition 6 formalizes this intuition.

Proposition 6 - Suppose that the investment function is concave on the interest rate, the markup of the supplier is sufficiently large, and that the interest-elasticity of demand for inputs is

greater than $\left(1-\frac{\pi}{1+r}\right) \frac{f+(1-f) \pi}{1+r-f-(1-f) \pi}$ at a zero interest rate. Then there is an equilibrium in which the supplier extends trade credit to both types of firms at a zero interest rate, even if the supplier cannot rescue any input when a customer becomes financially distressed (i.e., $\delta=0$ ).

Elliehausen and Wolken (1993), Petersen and Rajan (1994) and Ng, Smith and Smith (1999) all report that interest rates in trade credit markets are often standardized. And that, in some industries, suppliers waive interest when their customers repay the loans within 10 days. Waiving interest rates is consistent with Proposition 4 and 5 if the demand for inputs is elastic with respect to interest rates of loans of very short maturity. Moreover, Proposition 6 predicts that industries with strong monopoly power are more likely to waive interest upon an early repayment.

\section{Empirical Implications and Discussion}

\subsection{Do suppliers have incentives to release information truthfully?}

Consider an equilibrium with invariant interest rates and suppose that banks request information on the credit standing of a supplier's customer. Is it in the supplier's interest to release the information truthfully? As it turns out, announcing that the customer is a risky firm is a weakly dominant strategy for a supplier that can extend trade credit.

To see why, consider first the equilibrium in which the interest rate in the trade credit market is equal to the banking rate. In this equilibrium, the banking rate is an outside option for the firms that prevents the supplier from further increasing the interest rate. If the supplier can convincingly announce that the customer is a risky firm, banks will increase the interest rate accordingly, letting the supplier increase the interest rate as well. The higher interest rate moves the supplier closer to its unconstrained optimal. ${ }^{8}$ In turn, the banking rate is not relevant to the

\footnotetext{
${ }^{8}$ More formally, let $r_{B}^{R}$ be the interest rate that banks would have offered to a known risky firm. Competition
} 
supplier in the equilibrium in which the supplier waives interests. Hence, for a supplier that can extend trade credit, it is a dominant strategy to announce that a safe customer is risky.

Consider now a supplier that cannot extend trade credit. Here, the incentives to release information are reversed. If the supplier can convince the banks that its customers are safe, the banking rate will decrease accordingly, and the customer will demand more inputs. If the supplier has some monopoly power, then it is a strictly dominant strategy to announce that risky customers are safe. Otherwise, the supplier is indifferent about the banking rate and announcing that risky customers are safe is a weakly dominant strategy.

To be sure, banks can offer some revelation mechanism to suppliers. For instance, profitsharing mechanisms between a bank and a supplier should provide incentives for the supplier to credibly reveal private information. Still, we are not aware of any study that documents revelation mechanisms between banks and suppliers in standard trade-credit transactions. It is conceivable, though, that some sort of revelation mechanism is in place in project loans that are typically structured around very complex contracts. In these types of transactions, we do not expect an equilibrium with invariant interest rates.

\subsection{Monopoly power and informational advantage}

So far, we have imposed no constraints on the structure of the market for inputs. Suppliers can enjoy some monopoly power or face competitive forces that drives the input price down to the marginal cost $\left(\frac{p}{c}=1\right)$. The question that we address in this section is whether the equilibrium with invariant rates survives if competition in the market for inputs drives to zero not only operational profits but also financial profits.

Suppose that suppliers are all equally informed. In this case, there is no scope for a supplier to profit by lending to a safe firm. Competition extends to the trade credit market, driving down

among banks implies that the expected return of a banking loan at the interest rate $r_{B}^{R}$ equals the cost of funds $r$. Hence, $\pi\left(1+r_{B}^{R}\right)=(1+r)$ which implies that $r_{B}^{R}=\frac{1+r}{\pi}-1>r_{B}$. This means that the interest rate in banking loans increases if a supplier convinces the banks that the customer is a risky firm. As a result, the constraint in the supplier's program changes from $0 \leq r_{T}^{R} \leq r_{B}$ to $0 \leq r_{T}^{R} \leq r_{B}^{R}$. Since $r_{B}^{R}>r_{B}$, the constraint is relaxed, implying an increase in expected profits because a concave investment function implies that the supplier's profit function is concave. 
the interest rate of loans to safe firms to the riskless rate $r$. Note, though, that the equilibrium interest rate in loans to risky firms will not be equal to the riskless rate. In these loans, the supplier takes into account the probability $1-\pi$ that the debt contract will not be honored and that, in default, only $\delta I<I$ will be collected. As such, the interest rate $r_{T}^{R}$ that equals the expected return on the loan to the riskless rate is larger than the riskless rate $r$. And we conclude that competition among equally informed suppliers breaks down the equilibrium with invariance of interest rates in trade credit markets.

It is unlikely, nonetheless, that all suppliers of inputs are equally informed about their customers. It should be easier to learn private information about your best customers. Hence, although a threat to buy inputs from an alternative supplier may force a competitive price for the inputs, it should not break down the current supplier's informational advantage, which is all we need for the analysis of our model to hold.

\subsection{Invariance of interest rates and efficiency in default}

From Proposition 4 and 5, the equilibrium with invariant trade-credit rates requires that suppliers be more efficient than banks in salvaging assets of financially distressed firms. As it turns out, all that the equilibrium needs is that suppliers are more efficient lenders to risky firms than banks. For instance, a supplier might have no advantage in rescuing assets and yet, as Cuñat (2002) points out, be a more efficient lender due to a threat of stopping the supply of vital intermediate goods. Still, a low comparative advantage in salvaging assets of financially distressed firms makes

it more difficult for the threat of terminating the supply of inputs to be strong enough to assure that trade credit to risky firms is profitable. As we argue below, a testable implication of our model then follows.

Petersen and Rajan (1997) show that suppliers offer larger lines of credit to firms with a low fraction of their inventory in finished goods. Petersen and Rajan interpret their finding as evidence that suppliers have a stronger advantage of salvaging assets of firms that hold a low fraction of their inventory in finished goods. Intuitively, once firms transform intermediate goods into finished goods, suppliers can no longer use their regular sales force to sell the firms' inventory. In this spirit, our model predicts that suppliers are more likely to offer standardized interest rates in industries with a low fraction of finished goods in inventory. This prediction will 
be rejected if the invariance of the trade-credit rate reflects a preference of suppliers for adjusting input prices according to the risk of their customers. Or if trade-credit rates are equal to the banking rate simply because suppliers do not have superior information about their customers.

\subsection{Credit constraint and insurance against liquidity shocks}

In a sample of small firms in the National Survey of Small Business Finances (NSSBF), Petersen and Rajan (1997) find evidence that the demand for trade credit is inelastic. Given the high interest rate implicit in the standard discounts for early payments (e.g., 44 percent a year for the 2-10 net 30 loans), Petersen and Rajan argue that credit constrained firms are more likely to use trade credit. Yet, credit constraint cannot account for the invariance of the terms of credit at positive rates. In the absence of alternative sources of financing, suppliers are free to charge the interest rate that maximizes expected profits, which should vary with the borrowers' credit standing. The model thus predicts that standardized terms of trade credit should be available mostly for customers that are not credit constrained.

Likewise, the evidence that the terms of trade credit are industry-not-firm specific is at odds with arguments that relate high discounts in early payments (i.e., a high interest rate) with an insurance against liquidity shocks. For instance, Wilner (2000) points out that, to preserve longterm business relationships, suppliers have incentives to bail-out financially distressed customers. According to this argument, suppliers provide insurance against liquidity shocks that may lead their customers into financial distress. Anticipating these incentives, suppliers should embed the cost of the insurance in the trade-credit rate. Note, however, that the expected cost of this insurance premium should vary with the customer's risk, implying that, contrary to the existing evidence, the optimum trade-credit rate is firm specific.

\subsection{Uniqueness of equilibrium with invariant rates}

So far, we have restricted attention to equilibria in which, whenever possible, suppliers extend trade credit to both types of firms. In this class, Propositions 4 and 5 exhibit conditions for existence and uniqueness of an equilibrium in which, regardless of the firm's type, the tradecredit rate is either the banking rate or a zero interest rate. 
The reason for focusing on equilibria in which the supplier extends trade credit to both types of firms is quite clear. There cannot be variation of interest rates if the supplier offers trade credit to customers that are all in the same class of risk. Yet, as often happens in game theoretical models, there exists an equilibrium in which the supplier extends trade credit to safe firms only. ${ }^{9}$ In this section, we exhibit conditions under which this alternative equilibrium breaks down while preserving the equilibrium with invariance of interest rates.

To break down the equilibrium in which the supplier extends trade credit to safe firms only, it suffices to make it optimal for the supplier to offer trade credit to risky firms. As before, the net benefits of lending to risky firms depends on the banking rate. Our first task, therefore, is to characterize the banking rate in the alternative equilibrium.

Assume then that the supplier denies trade credit to risky firms. If so, risky firms borrow from banks to purchase inputs. Understanding the equilibrium strategies, banks update the beliefs upon the request of a banking loan, as follows. If the supplier can offer trade credit (an event with probability $x$ ) the firm that asks a banking loan is certain to be risky, and the loan will be repaid with probability $\pi$. If, however, the supplier cannot offer trade credit (an event with probability $1-x$ ), a firm that requests a banking loan is safe with probability $f$ - and the loan will be repaid with probability one - while it will be risky with probability $1-f$, in which case the loan will be repaid with probability $\pi$. The expected return on a banking loan at an interest rate $\tilde{r}_{B}$ is thus $\left(1+\tilde{r}_{B}\right)[(f+(1-f) \pi)(1-x)+\pi x]$. And the interest rate that makes the loan's expected return equal to the cost of funds $r$ solves:

$$
\left(1+\tilde{r}_{B}\right)[(f+(1-f) \pi)(1-x)+\pi x]=(1+r) .
$$

Solving for the banking rate in equation (16) yields

$$
\tilde{r}_{B}=\frac{1+r}{(f+(1-f) \pi)(1-x)+\pi x}-1 .
$$

\footnotetext{
${ }^{9}$ There is no equilibrium in which the supplier finances risky firms only. To see why, suppose by contradiction that such equilibrium exists. Still, a risky firm would borrow from banks when trade credit is not available. Hence, the banking rate must be higher than the riskless rate to assure banks their cost of funds. However, this very same banking rate, which is the safe firm's outside option, assures expected profits to trade credit to safe firms, breaking down the candidate for equilibrium. A similar argument breaks down equilibria in mixed stratetigies.
} 
One can easily verify that the interest rate $\tilde{r}_{B}$ is bigger than the banking rate $r_{B}$ of the equilibrium in which the supplier finances both types of firms (see equation (4)). Intuitively, the banking rate $\tilde{r}_{B}$ takes into account that, in the alternative equilibrium, a larger number of risk firms borrows from banks.

Now, let $r_{T}^{* R}\left(\tilde{r}_{B}\right)$ be the trade-credit rate that maximizes discounted profits conditioned on extending trade credit to the risky firm when the banking rate is $\tilde{r}_{B}$. Provided that we substitute $\tilde{r}_{B}$ for $r_{B}$, the maximization program that yields $r_{T}^{* R}\left(\tilde{r}_{B}\right)$ is identical to the program (12) that maximizes discounted profits the equilibrium with invariant trade-credit rates. Hence, Proposition 2 characterizes $r_{T}^{* R}\left(\tilde{r}_{B}\right)$, once we substitute $\tilde{r}_{B}$ for $r_{B}$.

We now have all the necessary ingredients to break down the equilibrium in which the supplier denies trade credit to risky firms. The equilibrium breaks down if the supplier is strictly better off extending trade credit to risky firms at the interest rate $r_{T}^{* R}\left(\tilde{r}_{B}\right)$, that is,

$$
\pi\left[p\left(\frac{1+r_{T}^{* R}\left(\tilde{r}_{B}\right)}{1+r}\right)-c\right] I\left(r_{T}^{* R}\left(\tilde{r}_{B}\right)\right)+(1-\pi)\left[\frac{\delta p}{(1+r)}-c\right] I\left(r_{T}^{* R}\left(\tilde{r}_{B}\right)\right)>(p-c) I\left(\tilde{r}_{B}\right) .
$$

Condition (18) requires that the discounted profits at the trade-credit rate $r_{T}^{* R}\left(\tilde{r}_{B}\right)$ outweigh profits when banks finance the risky firm at the banking rate $\tilde{r}_{B}$. Except for the strict inequality and the level of the banking rate, condition (18) is identical to condition (10), which makes it optimal for the supplier to lend to risky firms in the equilibrium that both types of firms have access to trade credit. As such, we can rewrite condition (18) as $\delta>\bar{\delta}\left(r_{T}^{* R}\left(\tilde{r}_{B}\right)\right)$, and from Propositions 2 and $3, \epsilon\left(\tilde{r}_{B}\right) \leq \frac{p \frac{1+\tilde{r}_{B}}{1+r}}{p \frac{1+\tilde{r}_{B}}{1+r}-c}$ is a sufficient condition for $r_{T}^{* S}\left(\tilde{r}_{B}\right)=r_{T}^{* R}\left(\tilde{r}_{B}\right)=\tilde{r}_{B}$, in which case the analysis in section 3.4 shows that $\delta>\bar{\delta}\left(r_{T}^{* R}\right)$ is equivalent to $\delta>1-\frac{\pi \tilde{r}_{B}-r}{1-\pi}$. Hence, a sufficient condition for breaking down the alternative equilibrium is $\epsilon\left(\tilde{r}_{B}\right) \leq \frac{p \frac{1+\tilde{r}_{B}}{1+r}}{p \frac{1+\tilde{r}_{B}}{1+r}-c}$ and $\delta>1-\frac{\pi \tilde{r}_{B}-r}{1-\pi}$.

Note, though, that we want to break down the alternative equilibrium while assuring existence of the equilibrium with invariant trade-credit rates. As it turns out, this twofold goal is achieved if $\tilde{r}_{B}=r_{B}$. In this case, $\epsilon\left(\tilde{r}_{B}\right) \leq \frac{p \frac{1+\tilde{r}_{B}}{1+r}}{p \frac{1+\tilde{r}_{B}}{1+r}-c}$ and $\delta>1-\frac{\pi \tilde{r}_{B}-r}{1-\pi}$ are equal to $\delta>\frac{(1+r) f}{f+(1-f) \pi}$ and $\epsilon\left(r_{B}\right) \leq \frac{p \frac{1+r_{B}}{1+r}}{p \frac{1+r_{B}}{1+r}-c}$, which, from Proposition 4, assure existence of the invariant equilibrium at the 
banking rate, if $\frac{f}{1-f} \leq \frac{\pi}{r}$.

But when is $\tilde{r}_{B}$ equal to $r_{B}$ ? A sufficient condition is that a supplier's decision to deny trade credit does not change the equilibrium banking rate. This additional condition will be satisfied, for example, if we assume that the firm's investment consists of purchases of several inputs from different monopolists, and that at least one of these suppliers is certain to be credit constrained. In this case, asking for banking loans to finance purchase of inputs does not convey information on the firm's type. More formally, the probability $x$ that trade credit satisfies all financing needs becomes arbitrarily close to zero. And, as one can easily check in equation (17), $\tilde{r}_{B}$ converges to $\frac{1+r}{f+\pi(1-f)}-1=r_{B}$

\section{Conclusions}

As several studies have documented (Elliehausen and Wolken (1993), Petersen and Rajan (1994) and Ng, Smith and Smith (1999)), the terms of trade credit in the U.S. are industry-not-firm specific. Since there is evidence that, vis-à-vis banks, suppliers are better informed about the economic health of their customers, the absence of firm-specific variation in the terms of trade credit is surprising.

This paper provides a reason for why interest rates in trade credit markets do not reflect suppliers' private information about their customers' credit risk. We argue that if the demand for intermediate goods is sufficiently inelastic with respect to interest rates, then suppliers have no incentives to undercut banks, regardless of the firm's type. The trade-credit rate thus converges to the cost of the customers' outside option (a banking loan), which, by its very nature, cannot reflect private information held by suppliers. In the other extreme, a sufficiently elastic demand may induce suppliers with strong monopoly power to waive interest, making private information once more irrelevant to the trade-credit rate.

Our model does not account for all the reported rigidity of interest rates in trade credit markets, though. In particular, under an inelastic demand, our model predicts different terms of trade credit to firms that, from the banks' perspective, are in different classes of risk. One possible reason for the seemingly excessive variation of trade-credit rates in our model is that we have ignored alternative mechanisms to vary the cost of trade credit. For instance, as Petersen 
and Rajan (1994) point out, suppliers allow for some variation in the actual trade-credit rate by selectively granting discounts for payments after the due date. Yet, these ex-post renegotiations are likely to be costly. To be sure, these costs elicit incentives for suppliers to vary interest rates with the borrowers' credit standing - as normally happens in banking loans (see Petersen and Rajan (1995)) - making it hard to believe that renegotiations of contracts account for all the reported rigidity of the terms of credit.

It is conceivable, however, that some suppliers use the price of their products - rather than interest rates - to adjust for the risk of credit of their customers. In this case, the invariance of the trade-credit rate would simply reflect its redundancy. According to this hypothesis, the rigidity of the terms of trade credit should not depend, for instance, on the costs that financially distressed firms may impose on the supplier. In contrast, our model predicts that the terms of trade credit are more likely to be standardized if these costs are low. 


\section{Appendix}

Proof of Proposition 1: The following lemma greatly simplifies the solution of the optimal trade-credit rate to safe firms.

Lemma 1: Define $\widetilde{r} \equiv \frac{c}{p}(1+r)-1$ and assume that $I\left(r_{T}^{S}\right)$ is twice differentiable and strictly concave. Thus, any trade-credit rate that satisfies the constraints (8) and (9) of program (7) belongs to the interval $\left[\max \{0, \widetilde{r}\}, r_{B}\right]$. Moreover, the profit function $\Phi_{T}^{S}\left(r_{T}^{S}\right)$ is positive and strictly concave for any $r_{T}^{R} \in\left[\widetilde{r}, r_{B}\right]$, with $\Phi_{T}^{S}\left(r_{T}^{S}\right)<0$, for any $r_{T}^{S} \in[0, \widetilde{r}]$.

Proof of Lemma 1 Differentiating twice the supplier's profit, $\Phi_{T}^{S}\left(r_{T}^{S}\right)=\left[p\left(\frac{1+r_{T}^{S}}{1+r}\right)-c\right] I\left(r_{T}^{S}\right)$, with respect to $r_{T}^{S}$ yields

$$
\begin{aligned}
\Phi_{T}^{\prime S}\left(r_{T}^{S}\right) & =I^{\prime}\left(r_{T}^{S}\right)\left[p\left(\frac{1+r_{T}^{S}}{1+r}\right)-c\right]+\left[\frac{p}{1+r}\right] I\left(r_{T}^{S}\right), \\
\Phi_{T}^{\prime \prime S}\left(r_{T}^{S}\right) & =I^{\prime \prime}\left(r_{T}^{S}\right)\left[p\left(\frac{1+r_{T}^{S}}{1+r}\right)-c\right]+2\left[\frac{p}{1+r}\right] I^{\prime}\left(r_{T}^{S}\right) .
\end{aligned}
$$

We can rewrite equation $(20)$ as $\Phi_{T}^{\prime \prime S}\left(r_{T}^{S}\right)=\frac{I^{\prime \prime}\left(r_{T}^{S}\right)}{I\left(r_{T}^{S}\right)} \Phi_{T}^{S}\left(r_{T}^{S}\right)+2\left[\frac{p}{1+r}\right] I^{\prime}\left(r_{T}^{S}\right)$. Now, $I^{\prime \prime}\left(r_{T}^{S}\right)<0$ and $I^{\prime}\left(r_{T}^{S}\right)<0$ imply that $\Phi_{T}^{\prime \prime S}\left(r_{T}^{S}\right)=\frac{I^{\prime \prime}\left(r_{T}^{S}\right)}{I\left(r_{T}^{S}\right)} \Phi_{T}^{S}\left(r_{T}^{S}\right)+2\left[\frac{p}{1+r}\right] I^{\prime}\left(r_{T}^{S}\right)<0$ for any $r_{T}^{S} \in\left[\widetilde{r}, r_{B}\right]$ because $\Phi_{T}^{S}\left(r_{T}^{S}\right)=\left[p\left(\frac{1+r_{T}^{S}}{1+r}\right)-c\right] I\left(r_{T}^{S}\right) \geq 0 \Longleftrightarrow r_{T}^{S} \geq \frac{c}{p}(1+r)-1 \equiv \widetilde{r}$. Hence, $\Phi_{T}^{S}\left(r_{T}^{S}\right)$ is positive and strictly concave in $\left[\widetilde{r}, r_{B}\right]$. To show that any trade credit rate that satisfies the constraints (8) and (9) of program (7) must belong to $\left[\max \{0, \widetilde{r}\}, r_{B}\right]$, note that, from the constraint (9), $\Phi_{T}^{S}\left(r_{T}^{S}\right) \geqslant(p-c) I\left(r_{B}\right) \geq 0 \Longrightarrow r_{T}^{S} \in\left[\widetilde{r}, r_{B}\right]$. Since $\widetilde{r}$ may be negative, the constraint (8) lets us restrict attention to $r_{T}^{S} \in\left[\max \{0, \widetilde{r}\}, r_{B}\right]$.

We are now ready to characterize the optimal trade-credit rate. By standard arguments (continuity and compactness), there is a trade-credit rate - call it $\widehat{r}_{T}^{S}$ - that maximizes $\Phi_{T}^{S}\left(r_{T}^{S}\right)$ in $\left[0, r_{B}\right]$. If the supplier does not extend trade credit, then the safe firm will borrow from banks at an interest rate $r_{B}$, buying $I\left(r_{B}\right)$ units of inputs. In the absence of trade credit, therefore, the supplier's profit is $(p-c) I\left(r_{B}\right)$. By extending trade credit at the interest rate $\widehat{r}_{T}^{S}$, the supplier profits $\Phi_{T}^{S}\left(\widehat{r}_{T}^{S}\right) \geq \Phi_{T}^{S}\left(r_{B}\right)=\left(p\left(\frac{1+r_{B}}{1+r}\right)-c\right) I\left(r_{B}\right)>(p-c) I\left(r_{B}\right)$, where the last inequality holds 
because $r_{B}>r$. Hence, it is optimal for the supplier to extend trade credit to safe firms at the interest rate $\widehat{r}_{T}^{S}$. If $\widehat{r}_{T}^{S} \in\left(0, r_{B}\right)$, then it is characterized by $\Phi_{T}^{\prime S}\left(\widehat{r}_{T}^{S}\right)=0$. Otherwise, the solution lies at zero or $r_{B}$. Below, we provide necessary and sufficient conditions for $\widehat{r}_{T}^{S}$.

Case 1: $\widehat{r}_{T}^{S}=0$. In this first case, reducing the interest rate as much as possible maximizes discounted profits. Hence, zero must satisfy the necessary first order condition: $\Phi_{T}^{\prime S}(0) \leq 0$. We want to write this first order condition as a restriction on the interest elasticity at zero. From equation $(19)$ and $I^{\prime}(0)<0, \Phi_{T}^{\prime S}(0)=I^{\prime}(0)\left[p\left(\frac{1}{1+r}\right)-c\right]+\left[\frac{p}{1+r}\right] I(0) \leq 0$ only if $p\left(\frac{1}{1+r}\right)-c>$ $0 \Longrightarrow \frac{p}{c}>1+r$. Hence, $\Phi_{T}^{\prime S}(0) \leq 0 \Longleftrightarrow \frac{I^{\prime}(0)}{I(0)} \leq-\frac{\frac{p}{1+r}}{\frac{p}{1+r}-c}$. Noting that the absolute value of the left-hand side of this latter inequality is our definition of the interest-elasticity of the demand for inputs at zero, $\epsilon(0)=-\frac{I^{\prime}(0)}{I(0)}$, it follows that $\Phi_{T}^{\prime S}(0) \leq 0 \Longleftrightarrow \epsilon(0) \geq \frac{\frac{p}{1+r}}{\frac{p}{1+r}-c}$. Conversely, assume that $\epsilon(0) \geq \frac{\frac{p}{1+r}}{\frac{p}{1+r}-c}$ and $\frac{p}{c}>1+r$. Then $\epsilon(0) \geq \frac{\frac{p}{1+r}}{\frac{p}{1+r}-c} \Longrightarrow \Phi_{T}^{\prime S}(0) \leq 0$. Moreover, $\frac{p}{c}>1+r \Longrightarrow$ $\widetilde{r} \equiv \frac{c}{p}(1+r)-1<0$. From the Lemma $1, \Phi_{T}^{S}\left(r_{T}^{S}\right)$ is strictly concave in $\left[0, r_{B}\right]$, implying that $\Phi_{T}^{\prime S}(0) \leq 0$ is sufficient for $\widehat{r}_{T}^{R}=0$. And we conclude that $\widehat{r}_{T}^{R}=0$ if and only if $\frac{p}{c}>1+r$ and $\epsilon(0) \geq \frac{\frac{p}{1+r}}{\frac{p}{1+r}-c}$.

Case 2: $\widehat{r}_{T}^{S}=r_{B}$. As in case 1 , a necessary condition for $\widehat{r}_{T}^{R}=r_{B}$ is that $\Phi_{T}^{\prime S}\left(r_{B}\right) \geq 0$. From equation (19), marginal profits are positive at $r_{B}$ if and only if $\Phi_{T}^{\prime S}\left(r_{B}\right)=\left[p\left(\frac{1+r_{B}}{1+r}\right)-c\right] I^{\prime}\left(r_{B}\right)+$ $\left[\frac{p}{1+r}\right] I\left(r_{B}\right) \geq 0$. Because $r_{B}>r$ and $p \geq c$, it is always true that $p\left(\frac{1+r_{B}}{1+r}\right)-c>0$. As a result, $\Phi_{T}^{\prime S}\left(r_{B}\right) \geq 0 \Longleftrightarrow \epsilon\left(r_{B}\right) \leq \frac{p \frac{1+r_{B}}{1+r}}{p \frac{1+r_{B}}{1+r}-c}$. Conversely, assume that $\epsilon\left(r_{B}\right) \leq \frac{p \frac{1+r_{B}}{1+r}}{p \frac{1+r_{B}}{1+r}-c} \Longleftrightarrow \Phi_{T}^{\prime S}\left(r_{B}\right) \geq$ 0 . By concavity of the profit function in the interval $\left[\widetilde{r}, r_{B}\right]$, the marginal profits decrease with the interest rate in the opportunity set. Hence, $\Phi_{T}^{\prime S}\left(r_{B}\right) \geq 0$ implies that profits increase with the trade-credit rate in the interval $\left[\widetilde{r}, r_{B}\right]$. To prove that $\widehat{r}_{T}^{S}=r_{B}$ it thus suffices to show that $\Phi_{T}^{S}\left(r_{T}^{S}\right)<0$ for any $r_{T}^{S} \in[0, \widetilde{r})$. But, as Lemma 1 shows, this is true by construction of $\widetilde{r}$. We thus conclude that $\widehat{r}_{T}^{S}=r_{B}$ if and only if $\epsilon\left(r_{B}\right) \leq \frac{p \frac{1+r_{B}}{1+r}}{p \frac{1+r_{B}}{1+r}-c}$.

Case 3: $\widehat{r}_{T}^{S} \in\left(0, r_{B}\right)$. Cases 1 and 2 provide necessary and sufficient conditions for the optimal trade-credit rate to be a corner solution. Since a solution to program (7) always exists, an interior solution obtains if and only if the conditions of cases 1 and 2 are not satisfied. That is, $\epsilon\left(r_{B}\right)>\frac{p \frac{1+r_{B}}{1+r}}{p \frac{1+r_{B}}{1+r}-c}$ to exclude the banking rate as the optimal and either $\frac{p}{c} \leq 1+r$ or $\epsilon(0)<\frac{\frac{p}{1+r}}{\frac{p}{1+r}-c}$ to exclude the zero interest rate. 
Proof of Proposition 2: The following lemma greatly simplifies the solution of the optimal trade-credit rate to risky firms:

Lemma 2: Define $\widetilde{r} \equiv \frac{1}{\pi}\left[\frac{c}{p}(1+r)-\delta(1-\pi)\right]-1$ and assume that $I\left(r_{T}^{R}\right)$ is twice differentiable and strictly concave. Thus, any trade-credit rate that satisfies the constraints (13) and (14) of program (12) belongs to the interval $\left[\max \{0, \widetilde{r}\}, r_{B}\right]$. Moreover, $\Phi_{T}^{R}\left(r_{T}^{R}\right)<0$, for any $r_{T}^{R} \in[0, \widetilde{r}]$ and the profit function $\Phi_{T}^{R}\left(r_{T}^{R}\right)$ is positive and strictly concave for any $r_{T}^{R} \in\left[\widetilde{r}, r_{B}\right]$.

Proof of Lemma 2 The discounted profit conditioned on extending trade credit to a risky firm at an interest rate $r_{T}^{R}$ is $\Phi_{T}^{R}\left(r_{T}^{R}\right)=\left\{\pi\left[p\left(\frac{1+r_{T}^{R}}{1+r}\right)-c\right]+(1-\pi)\left[\frac{\delta p}{(1+r)}-c\right]\right\} I\left(r_{T}^{R}\right)$. From the assumptions on the technology, $I\left(r_{T}^{R}\right)>0$ for any $r_{T}^{R} \in\left[0, r_{B}\right]$. Hence, conditioned on constraint (13) being satisfied, $\Phi_{T}^{R}\left(r_{T}^{R}\right) \geq 0$ if and only if $\pi\left[p\left(\frac{1+r_{T}^{R}}{1+r}\right)-c\right]+(1-\pi)\left[\frac{\delta p}{(1+r)}-c\right] \geq$ $0 \Longleftrightarrow r_{T}^{R} \geq \widetilde{r} \equiv \frac{1}{\pi}\left[\frac{c}{p}(1+r)-\delta(1-\pi)\right]-1$. It then follows from the constraint (14) and $(p-c) I\left(r_{B}\right) \geq 0$ that a necessary condition for a trade-credit rate $r_{T}^{R}$ to be optimal is that it belongs to $\left[\max \{0, \widetilde{r}\}, r_{B}\right]$. To show that $\Phi_{T}^{R}\left(r_{T}^{R}\right)$ is strictly concave in $\left[\widetilde{r}, r_{B}\right]$ we differentiate $\Phi_{T}^{R}\left(r_{T}^{R}\right)$ twice:

$$
\begin{aligned}
\Phi_{T}^{\prime R}\left(r_{T}^{R}\right) & =\left\{\pi\left[p\left(\frac{1+r_{T}^{R}}{1+r}\right)-c\right]+(1-\pi)\left[\frac{\delta p}{(1+r)}-c\right]\right\} I^{\prime}\left(r_{T}^{R}\right)+\frac{\pi p}{1+r} I\left(r_{T}^{R}\right), \\
\Phi_{T}^{\prime \prime}\left(r_{T}^{R}\right) & =\left\{\pi\left[p\left(\frac{1+r_{T}^{R}}{1+r}\right)-c\right]+(1-\pi)\left[\frac{\delta p}{(1+r)}-c\right]\right\} I^{\prime \prime}\left(r_{T}^{R}\right)+\frac{2 \pi p}{1+r} I^{\prime}\left(r_{T}^{R}\right) .
\end{aligned}
$$

Using $\Phi_{T}^{R}\left(r_{T}^{R}\right)=\left\{\pi\left[p\left(\frac{1+r_{T}^{R}}{1+r}\right)-c\right]+(1-\pi)\left[\frac{\delta p}{(1+r)}-c\right]\right\} I\left(r_{T}^{R}\right)$, we can rewrite equation (22) as $\Phi_{T}^{\prime \prime} R\left(r_{T}^{R}\right)=\frac{I^{\prime \prime}\left(r_{T}^{R}\right)}{I\left(r_{T}^{R}\right)} \Phi_{T}^{R}\left(r_{T}^{R}\right)+\frac{2 \pi p}{1+r} I^{\prime}\left(r_{T}^{R}\right)$. By assumption, $I^{\prime \prime}\left(r_{T}^{R}\right)<0$ and $I^{\prime}\left(r_{T}^{R}\right)<0$. Therefore, $\Phi_{T}^{R}\left(r_{T}^{R}\right) \geq 0$ is a sufficient condition for $\Phi_{T}^{\prime \prime} R\left(r_{T}^{R}\right)<0$. Since, $\Phi_{T}^{R}\left(r_{T}^{R}\right) \geq 0$ for any $r_{T}^{R} \in\left[\widetilde{r}, r_{B}\right]$, we conclude that, in this interval, $\Phi_{T}^{\prime \prime R}\left(r_{T}^{R}\right)<0$.

We are now ready to characterize the optimal trade-credit rate. By standard arguments (continuity and compactness), there is a trade-credit rate - call it $\widehat{r}_{T}^{R}$ - that maximizes $\Phi_{T}^{R}\left(r_{T}^{R}\right)$ in $\left[0, r_{B}\right]$. If $\Phi_{T}^{R}\left(\widehat{r}_{T}^{R}\right)<(p-c) I\left(r_{B}\right)$, then, rather than extending trade credit at $\widehat{r}_{T}^{R}$, it is more profitable to let banks finance the risky firms at the interest rate $r_{B}$. Since $\Phi_{T}^{R}\left(\widehat{r}_{T}^{R}\right) \geq \Phi_{T}^{R}\left(r_{T}^{R}\right)$ for any $r_{T}^{R} \in\left[0, r_{B}\right], \Phi_{T}^{R}\left(\widehat{r}_{T}^{R}\right)<(p-c) I\left(r_{B}\right)$ implies that it is optimal not to extend trade credit to the 
risky firm, regardless of the trade-credit rate. Conversely, $\Phi_{T}^{R}\left(\widehat{r}_{T}^{R}\right) \geq(p-c) I\left(r_{B}\right)$ implies that it is worthwhile extending trade credit to risky firms at the interest rate $\widehat{r}_{T}^{R}$. We thus conclude that $\widehat{r}_{T}^{R}$ is the optimal trade-credit rate if and only if $\Phi_{T}^{R}\left(\widehat{r}_{T}^{R}\right) \geq(p-c) I\left(r_{B}\right)$, or equivalently, $\delta \geq \bar{\delta}\left(\widehat{r}_{T}^{R}\right)$, where $\bar{\delta}\left(\widehat{r}_{T}^{R}\right)$ solves $\Phi_{T}^{R}\left(\widehat{r}_{T}^{R}\right)=\left\{\pi\left[p\left(\frac{1+\widehat{r}_{T}^{R}}{1+r}\right)-c\right]+(1-\pi)\left[\frac{\bar{\delta}\left(\widehat{r}_{T}^{R}\right) p}{(1+r)}-c\right]\right\} I\left(\widehat{r}_{T}^{R}\right)=(p-c) I\left(r_{B}\right)$. Now, whether $\Phi_{T}^{R}\left(\widehat{r}_{T}^{R}\right) \geq(p-c) I\left(r_{B}\right)$ or not $\widehat{r}_{T}^{R}$ is either in one of the corners - zero or $r_{B}-$ or it lies in open interval $\left(0, r_{B}\right)$, satisfying $\Phi_{T}^{\prime R}\left(\widehat{r}_{T}^{R}\right)=0$. Below, we provide necessary and sufficient conditions for each of these cases.

Case 1: $\widehat{r}_{T}^{R}=0$. For the profit maximizer interest to be zero, it must satisfy the necessary first order condition $\Phi_{T}^{R}(0) \leq 0$. We want to write this first order condition as a restriction on the interest elasticity at zero. Since $\frac{\pi p}{1+r} I(0)>0$ and $I^{\prime}(0)<0, \Phi_{T}^{\prime R}(0)=$ $\left\{\pi\left[\frac{p}{1+r}-c\right]+(1-\pi)\left[\frac{\delta p}{(1+r)}-c\right]\right\} I^{\prime}(0)+\frac{\pi p}{1+r} I(0) \leq 0$ only if $\pi\left[\frac{p}{1+r}-c\right]+(1-\pi)\left[\frac{\delta p}{(1+r)}-c\right]>$ 0 , or equivalently, $\frac{p}{c}>\frac{1+r}{\pi+(1-\pi) \delta}$. For $\pi\left[\frac{p}{1+r}-c\right]+(1-\pi)\left[\frac{\delta p}{(1+r)}-c\right]>0$, simple algebra shows that $\Phi_{T}^{\prime R}(0) \leq 0 \Longleftrightarrow \epsilon(0) \geq \frac{\frac{\pi p}{1+r}}{\frac{\pi p}{1+r}+(1-\pi) \frac{\delta p}{1+r}-c}$. Now, the second condition for $\widehat{r}_{T}^{R}=0$ to solve the supplier's problem is $\Phi_{T}^{R}(0) \geq(p-c) I\left(r_{B}\right) \Longleftrightarrow \delta \geq \bar{\delta}(0)$. Since we have already established $\frac{p}{c}>\frac{1+r}{\pi+(1-\pi) \delta}>1$ as a necessary condition for $\widehat{r}_{T}^{R}=0, \frac{p}{c}>1 \Longrightarrow(p-c) I\left(r_{B}\right)>0$. As a result, $\frac{p}{c}>1$ and $\Phi_{T}^{R}(0) \geq(p-c) I\left(r_{B}\right)>0$ implies that $\pi\left[p\left(\frac{1}{1+r}\right)-c\right]+(1-\pi)\left[\frac{\delta p}{(1+r)}-c\right]>0$, or equivalently $\frac{p}{c}>\frac{1+r}{\pi+(1-\pi) \delta}$. And we conclude that $\frac{p}{c}>\frac{1+r}{\pi+(1-\pi) \delta}$ is redundant, letting us write $\frac{p}{c}>1, \Phi_{T}^{R}(0) \geq(p-c) I\left(r_{B}\right)$, and $\epsilon(0) \geq \frac{\frac{\pi p}{1+r}}{\frac{\pi p}{1+r}+(1-\pi) \frac{\delta p}{1+r}-c}$ as necessary conditions for $\widehat{r}_{T}^{R}=0$.

Conversely, assume that $\frac{p}{c}>1, \Phi_{T}^{R}(0) \geq(p-c) I\left(r_{B}\right)$, and $\epsilon(0) \geq \frac{\frac{\pi p}{1+r}}{\frac{\pi p}{1+r}+(1-\pi) \frac{\delta p}{1+r}-c}$. Since $\underline{p}>1$ implies that $(p-c) I\left(r_{B}\right)>0, \Phi_{T}^{R}(0) \geq(p-c) I\left(r_{B}\right)>0 \Longrightarrow \Phi_{T}^{R}(0)>0$. Because profits are strictly positive at zero, we have that $\pi\left[p\left(\frac{1}{1+r}\right)-c\right]+(1-\pi)\left[\frac{\delta p}{(1+r)}-c\right]>0$, in which case $\epsilon(0) \geq \frac{\frac{\pi p}{1+r}}{\frac{\pi p}{1+r}+(1-\pi) \frac{\delta p}{1+r}-c} \Longleftrightarrow \Phi_{T}^{\prime R}(0)=\left\{\pi\left[p\left(\frac{1}{1+r}\right)-c\right]+(1-\pi)\left[\frac{\delta p}{(1+r)}-c\right]\right\} I^{\prime}(0)+\frac{\pi p}{1+r} I(0) \geq$ 0 . The zero interest rate, therefore, satisfies the necessary first order condition for maximizing discounted profits in $\left[0, r_{B}\right]$. Now, from Lemma $2, \Phi_{T}^{R}\left(r_{T}^{R}\right)$ is positive and strictly concave in $\left[\max \{0, \widetilde{r}\}, r_{B}\right]$; an interval that is actually equal to $\left[0, r_{B}\right]$ because $\Phi_{T}^{R}(0)>0 \Longrightarrow \widetilde{r}<0$. Hence, $\Phi_{T}^{\prime R}(0) \geq 0$ is necessary and sufficient for the zero interest rate to maximize discounted profits in $\left[0, r_{B}\right]$. But then $\Phi_{T}^{R}(0) \geq(p-c) I\left(r_{B}\right)$ (or equivalently $\delta \geq \bar{\delta}(0)$ ) suffices for zero to be the optimal trade-credit rate. And, we conclude that $\delta \geq \bar{\delta}(0), \epsilon(0) \geq \frac{\frac{\pi p}{1+r}}{\frac{\pi p}{1+r}+(1-\pi) \frac{\delta p}{1+r}-c}$, and $\frac{p}{c}>1$ are necessary and sufficient conditions for the zero trade-credit rate to solve the supplier's 
problem.

Case 2: $\widehat{r}_{T}^{R}=r_{B}$. Assume first that $\delta=\bar{\delta}\left(r_{B}\right) \equiv 1-\frac{\pi r_{B}-r}{1-\pi}$ and $p=c$. By construction of $\bar{\delta}\left(r_{B}\right), \delta=\bar{\delta}\left(r_{B}\right)$ implies that profits are just enough to make it worthwhile extending trade credit to the risky firm at $r_{B}$, that is, $\Phi_{T}^{R}\left(r_{B}\right)=(p-c) I\left(r_{B}\right)$. Since we also assume that $p=c$, it follows from $\Phi_{T}^{R}\left(r_{B}\right)=(p-c) I\left(r_{B}\right)$ that $\Phi_{T}^{R}\left(r_{B}\right)=0$. Hence, $\widetilde{r}=r_{B}$ and, from Lemma $2, \Phi_{T}^{R}\left(r_{T}^{R}\right)<0$ for any $r_{T}^{R} \in\left[0, r_{B}\right)$. Therefore, $r_{B}$ is the unique solution to the supplier's problem if $\delta=\bar{\delta}\left(r_{B}\right)$ and $p=c$. Now, $p>c \Longrightarrow(p-c) I\left(r_{B}\right)>0$. Hence, if $r_{B}$ satisfies $\Phi_{T}^{R}\left(r_{B}\right) \geq(p-c) I\left(r_{B}\right)$, it must be the case that $\Phi_{T}^{R}\left(r_{B}\right)>0$. Likewise, $\delta>\bar{\delta}\left(r_{B}\right)$ and $p \geq c$ implies that $\Phi_{T}^{R}\left(r_{B}\right)>(p-c) I\left(r_{B}\right) \geq 0 \Longrightarrow \Phi_{T}^{R}\left(r_{B}\right)>0$. It then follows that $r_{B}$ solves the supplier's problem with $\Phi_{T}^{R}\left(r_{B}\right)=0$ if and only if $\delta=\bar{\delta}\left(r_{B}\right)$ and $p=c$.

Assume now that $\delta \geq \bar{\delta}\left(r_{B}\right)$ and $p \geq c$, with strict inequality for at least one of the two. From the previous paragraph, $\Phi_{T}^{R}\left(r_{B}\right)>0$ and, therefore, $r_{B}>\widetilde{r}$. From Lemma 2, $\Phi_{T}^{R}\left(r_{T}^{R}\right)$ is strictly concave in $\left[\widetilde{r}, r_{B}\right]$ and $\Phi_{T}^{R}\left(r_{T}^{R}\right)<0$ for any $r_{T}^{R} \in[0, \widetilde{r})$. Hence, $r_{B}$ maximizes $\Phi_{T}^{R}\left(r_{T}^{R}\right)$ in $\left[0, r_{B}\right]$ if and only if $\Phi_{T}^{\prime R}\left(r_{B}\right)=\left\{\pi\left[p\left(\frac{1+r_{B}}{1+r}\right)-c\right]+(1-\pi)\left[\frac{\delta p}{(1+r)}-c\right]\right\} I^{\prime}\left(r_{B}\right)+$ $\frac{\pi p}{1+r} I\left(r_{B}\right) \geq 0$. Since $\Phi_{T}^{R}\left(r_{B}\right)>0 \Longleftrightarrow \pi\left[p\left(\frac{1+r_{B}}{1+r}\right)-c\right]+(1-\pi)\left[\frac{\delta p}{(1+r)}-c\right]>0$, we can rewrite $\left\{\pi\left[p\left(\frac{1+r_{B}}{1+r}\right)-c\right]+(1-\pi)\left[\frac{\delta p}{(1+r)}-c\right]\right\} I^{\prime}\left(r_{B}\right)+\frac{\pi p}{1+r} I\left(r_{B}\right) \geq 0$ as $\epsilon\left(r_{B}\right) \leq \frac{\pi p \frac{1+r_{B}}{1+r}}{\pi p \frac{1+r_{B}}{1+r}+(1-\pi) \frac{\delta p}{1+r}-c}$, where $\epsilon\left(r_{T}^{R}\right)=-\frac{\left(1+r_{T}^{R}\right) I^{\prime}\left(r_{T}^{R}\right)}{I\left(r_{T}^{R}\right)}$. Therefore, $r_{B}$ maximizes discounted profits in $\left[0, r_{B}\right]$ if and only if $\epsilon\left(r_{B}\right) \leq \frac{\pi p \frac{1+r_{B}}{1+r}}{\pi p \frac{1+r_{B}}{1+r}+(1-\pi) \frac{\delta p}{1+r}-c}$. We thus conclude that $r_{B}$ solves the supplier's problem if $p=c$ and $\delta=\bar{\delta}\left(r_{B}\right)$ or if $\epsilon\left(r_{B}\right) \leq \frac{\pi p \frac{1+r_{B}}{1+r}}{\pi p \frac{1+r_{B}}{1+r}+(1-\pi) \frac{\delta p}{1+r}-c}$ and $\delta \geq \bar{\delta}\left(r_{B}\right)$.

Case 3: $\widehat{r}_{T}^{R} \in\left(0, r_{B}\right)$. Since there is always a trade-credit rate $\widehat{r}_{T}^{R}$ that maximizes discounted profits in $\left[0, r_{B}\right]$, a solution to program (12) exists if and only if $\delta \geq \bar{\delta}\left(\widehat{r}_{T}^{R}\right)$. Hence, provided that $\delta \geq$ $\bar{\delta}\left(\widehat{r}_{T}^{R}\right)$, an interior solution obtains if and only if the necessary and sufficient conditions are not satisfied for $\widehat{r}_{T}^{R} \in\left\{0, r_{B}\right\}$, that is, $\Phi_{T}^{\prime R}(0)>0$ and $\Phi_{T}^{\prime R}\left(r_{B}\right)<0$. Consider first the zero interest rate. Since $I^{\prime}(0)<0$, equation $(21)$ and $\pi\left[p\left(\frac{1}{1+r}\right)-c\right]+(1-\pi)\left[\frac{\delta p}{(1+r)}-c\right] \leq 0$ (or equivalently $\frac{p}{c} \leq$ $\left.\frac{1+r}{\pi+(1-\pi) \delta}\right)$ imply that $\Phi_{T}^{\prime R}(0)=\left\{\pi\left[p\left(\frac{1}{1+r}\right)-c\right]+(1-\pi)\left[\frac{\delta p}{(1+r)}-c\right]\right\} I^{\prime}(0)+\frac{\pi p}{1+r} I(0)>0$, violating the necessary and sufficient condition for the interest rate to be optimal. If $\pi\left[p\left(\frac{1}{1+r}\right)-c\right]+$ $(1-\pi)\left[\frac{\delta p}{(1+r)}-c\right]>0$ (or equivalently $\frac{p}{c}>\frac{1+r}{\pi+(1-\pi) \delta}$ ), one can easily check that the necessary and sufficient condition breaks down if and only if $\epsilon(0)<\frac{\frac{\pi p}{1+r}}{\frac{\pi p}{1+r}+(1-\pi) \frac{\delta p}{1+r}-c}$. The restrictions from case 1 
are, therefore, $\frac{p}{c} \leq \frac{1+r}{\pi+(1-\pi) \delta}$; or $\epsilon(0)<\frac{\frac{\pi p}{1+r}}{\frac{\pi p}{1+r}+(1-\pi) \frac{\delta p}{1+r}-c}$ and $\frac{p}{c}>\frac{1+r}{\pi+(1-\pi) \delta}$. Unlike the zero rate, we cannot break down the optimality of the banking rate by requiring that requiring that $\Phi_{T}^{R}\left(r_{B}\right) \leq 0$ because, from Lemma 2 , discounted profits would be negative for any $\widehat{r}_{T}^{R} \in\left(0, r_{B}\right)$, making it impossible for $\Phi_{T}^{R}\left(\widehat{r}_{T}^{R}\right)>(p-c) I\left(r_{B}\right)$ to be satisfied. Note, however, that $\Phi_{T}^{R}\left(r_{B}\right)>0$ is redundant if we assure the optimality of $\widehat{r}_{T}^{R} \in\left(0, r_{B}\right)$. By strict concavity of $\Phi_{T}^{R}\left(r_{T}^{R}\right)$ in $\left[\widehat{r}_{T}^{R}, r_{B}\right]$, we have $\Phi_{T}^{R}\left(\widehat{r}_{T}^{R}\right)>\Phi_{T}^{R}\left(r_{B}\right) \geq 0$. But then $\Phi_{T}^{R}\left(\widehat{r}_{T}^{R}\right)=\left\{\pi\left[p\left(\frac{1+\widehat{r}_{T}^{R}}{1+r}\right)-c\right]+(1-\pi)\left[\frac{\delta p}{(1+r)}-c\right]\right\} I\left(\widehat{r}_{T}^{R}\right)>0$ implies $\left\{\pi\left[p\left(\frac{1+r_{B}}{1+r}\right)-c\right]+(1-\pi)\left[\frac{\delta p}{(1+r)}-c\right]\right\}>0$, for $r_{B}>\widehat{r}_{T}^{R}$. It then follows that $\Phi_{T}^{R}\left(r_{B}\right)=$ $\left\{\pi\left[p\left(\frac{1+r_{B}}{1+r}\right)-c\right]+(1-\pi)\left[\frac{\delta p}{(1+r)}-c\right]\right\} I\left(r_{B}\right)>0$. From the analysis in case 2 , a necessary condition for $r_{B}$ to be optimal when $\Phi_{T}^{R}\left(r_{B}\right)>0$ is $\epsilon\left(r_{B}\right) \leq \frac{\pi p \frac{1+r_{B}}{1+r}}{\pi p \frac{1+r_{B}}{1+r}+(1-\pi) \frac{\delta p}{1+r}-c}$. Hence, we rule out the optimality of $r_{B}$ if $\epsilon\left(r_{B}\right)>\frac{\pi p \frac{1+r_{B}}{1+r}}{\pi p \frac{1+r_{B}}{1+r}+(1-\pi) \frac{\delta p}{1+r}-c}$. And we conclude that $\widehat{r}_{T}^{R} \in\left(0, r_{B}\right)$ if and only if $\Phi_{T}^{\prime R}\left(\widehat{r}_{T}^{R}\right)=0, \delta \geq \bar{\delta}\left(\widehat{r}_{T}^{R}\right), \epsilon(0)<\frac{\frac{\pi p}{1+r}}{\frac{\pi p}{1+r}+(1-\pi) \frac{\delta p}{1+r}-c}$ and $\frac{p}{c}>\frac{1+r}{\pi+(1-\pi) \delta}$;or $\frac{p}{c} \leq \frac{1+r}{\pi+(1-\pi) \delta}$ and $\epsilon\left(r_{B}\right)>\frac{\pi p \frac{1+r_{B}}{1+r}}{\pi p \frac{1+r_{B}}{1+r}+(1-\pi) \frac{\delta p}{1+r}-c}$.

Proof of Proposition 3: Suppose that it optimal for the supplier to offer the highest possible interest rate to a safe firm, that is, $r_{T}^{S}\left(r_{B}\right)=r_{B}$. We want to show that either it is not optimal to extend trade credit to the risky firm or it is also optimal for the supplier to offer the banking rate to the risky firm. From Proposition $1, r_{T}^{S}\left(r_{B}\right)=r_{B}$ if and only if $\epsilon\left(r_{B}\right) \leq \bar{\epsilon}^{S}\left(r_{B}\right) \equiv \frac{p \frac{1+r_{B}}{1+r}}{p \frac{1+r_{B}}{1+r}-c}$. To compare this restriction with those that arise from the optimal trade-credit rate with a risky firm, we look at three mutually exclusive and exhaustive possibilities. If $\frac{p}{c}=1$ and $\delta=\bar{\delta}\left(r_{B}\right)$, then, from Proposition 2, $r_{T}^{R}\left(r_{B}\right)=r_{B}$, as we wanted to show. If $\delta<\bar{\delta}\left(r_{B}\right)$, then, regardless of the mark-up $\frac{p}{c}$, it is not optimal to extend trade credit to the risky firm. The remaining possibility is if $\delta \geq \bar{\delta}\left(r_{B}\right)$ and $\frac{p}{c} \geq 1$, with at least one strict inequality. In this case, the proof of Proposition 2 shows that $r_{T}^{R}\left(r_{B}\right)=r_{B}$ if and only if $\epsilon\left(r_{B}\right) \leq \frac{\pi p \frac{1+r_{B}}{1+r}}{\pi p \frac{1+r_{B}}{1+r}+(1-\pi) \frac{\delta p}{1+r}-c} \equiv \bar{\epsilon}^{R}\left(r_{B}\right)$. One can easily check that $\bar{\epsilon}^{S}\left(r_{B}\right)<\bar{\epsilon}^{R}\left(r_{B}\right) \Longleftrightarrow \frac{\delta p}{1+r}<c$; and this latter inequality holds because, by assumption, rescuing unused inputs is not enough to assure nonnegative profits when the risky firm fails. It then follows that $\epsilon\left(r_{B}\right) \leq \bar{\epsilon}^{S}\left(r_{B}\right) \Longrightarrow \epsilon\left(r_{B}\right)<\bar{\epsilon}^{R}\left(r_{B}\right)$. Hence, if $r_{B}$ is the optimal trade-credit rate to safe firms, then either it is not optimal to extend trade credit to the risky firm or $r_{B}$ is the optimal trade-credit rate to risky firms as well. Conversely, $r_{B}$ is the optimal trade-credit rate with a risky firm but not with a safe firm if $\epsilon\left(r_{B}\right) \in\left(\bar{\epsilon}^{S}\left(r_{B}\right), \bar{\epsilon}^{R}\left(r_{B}\right)\right)$ or $\epsilon\left(r_{B}\right)>\bar{\epsilon}^{S}\left(r_{B}\right)$ 
with $p=c$ and $\delta=\bar{\delta}\left(r_{B}\right)$.

Next, we show that $r_{T}^{R}\left(r_{B}\right)=0$ implies that $r_{T}^{S}\left(r_{B}\right)=0$. From Proposition 2 , the optimal trade-credit rate with a risky firm is zero if and only if $\epsilon(0) \geq \frac{\frac{\pi p}{1+r}}{\frac{\pi p}{1+r}+(1-\pi) \frac{\delta p}{1+r}-c} \equiv \bar{\epsilon}^{R}(0), \frac{P}{c}>1$ and $\delta \geq \bar{\delta}(0)$. Moreover, the proof of Proposition 2 (case1) shows that $\frac{P}{c}>1$ and $\delta \geq \bar{\delta}(0)$ imply $\frac{p}{c}>\frac{1+r}{\pi+\delta(1-\pi)} \equiv \bar{p}^{R}$. Hence, $r_{T}^{R}\left(r_{B}\right)=0$ implies that $\epsilon(0) \geq \bar{\epsilon}^{R}(0)$ and $\frac{p}{c} \geq \bar{p}^{R}$. In turn Proposition 1, tells us that, conditioned on the firm being safe, zero is the optimal trade credit rate if and only if $\epsilon(0) \geq \frac{\frac{p}{p}}{\frac{1+r}{1+r}-c} \equiv \bar{\epsilon}^{S}(0)$ and $\frac{p}{c} \geq 1+r \equiv \bar{p}^{S}$. Simple algebra shows that $\bar{\epsilon}^{S}(0)<\bar{\epsilon}^{R}(0) \Longleftrightarrow \frac{\delta p}{1+r}<c$. As we have already argued, this latter inequality holds because we assume that the supplier loses when the risky firm fails. Accordingly, $\epsilon(0) \geq \bar{\epsilon}^{R}(0) \Longrightarrow$ $\epsilon(0) \geq \bar{\epsilon}^{S}(0)$. Likewise, $\bar{p}^{S}<\bar{p}^{R} \Longleftrightarrow \delta<1$, which is true because $\delta=1$ would have implied that, contrary to what we assume, the failure of the risky firm imposes no loss on the supplier. It then follows that $\frac{p}{c} \geq \bar{p}^{R} \Longrightarrow \frac{p}{c} \geq \bar{p}^{S}$, and we conclude that the parameters of the model that satisfy the conditions for waiving interest of a risky firm also satisfy the conditions for zero to be optimal with a safe firm. In contrast, zero is the optimal trade-credit rate when the firm is safe but not when the firm is risky if either $\epsilon(0) \in\left[\bar{\epsilon}^{S}(0), \bar{\epsilon}^{R}(0)\right)$ or $\frac{p}{c} \in\left[\bar{p}^{S}(0), \bar{p}^{R}(0)\right)$.

Finally, we show that, in case of interior solutions, the optimal trade-credit rate with a risky firm is larger than the optimal rate with a safe firm. By combining equations (19) in the proof of Lemma 1 and (21) in the proof of Lemma 2, we can write:

$$
\Phi_{T}^{\prime R}(\widehat{r})=\pi \Phi_{T}^{\prime S}(\widehat{r})+(1-\pi)\left(\frac{\delta p}{1+r}-c\right) I^{\prime}(\widehat{r})
$$

Plugging $\widehat{r}=\widehat{r}_{T}^{S}$ into equation (23) and taking into account that $\Phi_{T}^{\prime S}\left(\widehat{r}_{T}^{S}\right)=0$ yields $\Phi_{T}^{\prime R}\left(\widehat{r}_{T}^{S}\right)=$ $(1-\pi)\left(\frac{\delta p}{1+r}-c\right) I^{\prime}\left(\widehat{r}_{T}^{S}\right)$, which is positive because the demand for inputs decreases with the trade credit rate and $\frac{\delta p}{1+r}-c<0$ by the assumption that the supplier loses when the risky firm fails. It then follows from $\Phi_{T}^{\prime R}\left(\widehat{r}_{T}^{S}\right)>0$ that $\widehat{r}_{T}^{S}<\widehat{r}_{T}^{R}$ because $\Phi_{T}^{R}\left(r_{T}^{R}\right)$ is strictly concave and $\Phi_{T}^{\prime R}\left(\widehat{r}_{T}^{R}\right)=0$.

Proof of Proposition 5: The goal is to show that there exists $\delta \in(0,1)$ such that $\delta \geq \bar{\delta}(0)=$ $\frac{c}{p}\left(\frac{1+r}{1-\pi}\right)\left(\frac{I(0)-I\left(r_{B}\right)}{I(0)}\right)+\frac{(1+r) I\left(r_{B}\right)-\pi I(0)}{(1-\pi) I(0)}$ with $\frac{p}{c}>1$ and $\epsilon(0) \geq \frac{\frac{\pi p}{1+r}}{\frac{\pi p}{1+r}+(1-\pi) \frac{\delta p}{1+r}-c}$. To do this, note first that since the demand for inputs decreases with the interest rate, $r_{B}>0$ implies that $I\left(r_{B}\right)<I(0)$. Now, define $\frac{I\left(r_{B}\right)}{I(0)}=\beta\left(r_{B}\right) \in(0,1)$. Since $r_{B}$ is a function of $\pi$ and $r$, so 
is $\beta\left(r_{B}\right)$ and we can write $\beta(\pi, r)$. Hence, we can once more rewrite the condition on $\delta$ as $\delta \geq \beta(\pi, r)\left(\frac{1+r}{1-\pi}\right)\left(1-\frac{c}{p}\right)-\left[\frac{\pi}{1-\pi}-\frac{c}{p}\left(\frac{1+r}{1-\pi}\right)\right]$.

To make it explicit that $\bar{\delta}(0)$ depends on $\pi$ and $r$, call $\bar{\delta}(0, \pi, r)=\beta(\pi, r)\left(\frac{1+r}{1-\pi}\right)\left(1-\frac{c}{p}\right)-$ $\left[\frac{\pi}{1-\pi}-\frac{c}{p}\left(\frac{1+r}{1-\pi}\right)\right]$. If $\bar{\delta}(0, \pi, r)<1$ for some parameter values with $\frac{p}{c}>1$ and $\epsilon(0) \geq \frac{\frac{\pi p}{1+r}}{\frac{\pi p}{1+r}+(1-\pi) \frac{\delta p}{1+r}-c}$, then the proof is done because we can make $\delta$ as close to one as needed. As a first step of the proof we will show that this is indeed possible for $\pi=0$.

Evaluating $\bar{\delta}(0, \pi, r)$ at $\pi=0$ yields $\bar{\delta}(0,0, r)=\beta(0, r)(1+r)\left(1-\frac{c}{p}\right)+\frac{c(1+r)}{p}$. We claim that the set of parameters that satisfy $\beta(0, r)(1+r)\left(1-\frac{c}{p}\right)+\frac{c(1+r)}{p}<1$ is not empty. Plugging $r_{B}=$ $\frac{1+r}{f+\pi(1-f)}-1$ into the definition of $\beta(\pi, r)$ and making $\pi=0$ in $\beta(0, r)(1+r)\left(1-\frac{c}{p}\right)+\frac{c(1+r)}{p}<1$ yields $I\left(\frac{1+r}{f}-1\right)(1+r)\left(1-\frac{c}{p}\right)<I(0)\left[1-\frac{c(1+r)}{p}\right]$. For $r=0$ and $\frac{p}{c}>1$, this inequality is equivalent to $I\left(\frac{1}{f}-1\right) 0<I(0)$, which holds because $I(\cdot)$ decreases with the interest rate and $f<1$. We now prove that the inequality holds for any $r \geq 0$, provided that the markup $\frac{p}{c}$ is sufficiently large. Define $\varphi(r)=I\left(\frac{1+r}{f}-1\right)(1+r)\left(1-\frac{c}{p}\right)-I(0)\left[1-\frac{c(1+r)}{p}\right]$. Thus, it suffices to show that $\varphi$ decreases with $r$ for $\frac{p}{c}$ sufficiently large. Differentiating $\varphi$ obtains $\varphi^{\prime}(r)=I\left(r_{B}\right)+I^{\prime}\left(r_{B}\right) \frac{1+r}{f}-I(0) \frac{c}{p}$, after taking into account that $\frac{1+r}{f}-1$ is $r_{B}$ evaluated at $\pi=0$. Hence, after some algebra, $\varphi^{\prime}(r)=I\left(r_{B}\right)\left(1-\frac{c}{p}\right)\left(1-\epsilon\left(r_{B}\right)\right)+I(0) \frac{c}{p} \leq 0$ for $\frac{c}{p}$ sufficiently large if and only if $\epsilon\left(r_{B}\right) \geq 1$. To show that $\epsilon\left(r_{B}\right) \geq 1$ note that, by concavity of the demand for inputs, $\epsilon(0) \geq 1 \Longrightarrow \epsilon\left(r_{B}\right)>1$, and, from Proposition 3, zero is the optimal trade-credit rate with a risky firm only if its is also optimal with a safe firm. From Proposition 1, zero is optimal with a safe firm if and only if $\epsilon(0) \geq \frac{\frac{p}{1+r}}{\frac{1}{1+r}-c}>1$. As a result, $\epsilon\left(r_{B}\right)>1$ and we have proved that $\bar{\delta}(0, \pi, r)<1$ for $\frac{p}{c}$ sufficiently large.

The final step for proving existence is to show that $\bar{\delta}(0, \pi, r)<1$ for $\frac{p}{c}$ sufficiently large and $\pi \neq 0$. By continuity of $\bar{\delta}(0, \pi, r)=\beta(\pi, r)\left(\frac{1+r}{1-\pi}\right)\left(1-\frac{c}{p}\right)-\left[\frac{\pi}{1-\pi}-\frac{c}{p}\left(\frac{1+r}{1-\pi}\right)\right], \bar{\delta}(0,0, r)<1$ implies that $\bar{\delta}(0, \pi, r)<1$ for any $r>0$ and $\pi$ positive but sufficiently close to zero. In particular, it holds for the $r^{*}$ that solves $1-\frac{c}{p}\left(1+r^{*}\right)=0$. For such $r^{*}, \bar{\delta}\left(0, \pi, r^{*}\right)<1$ if $\pi$ is sufficiently close to zero and $\frac{p}{c}$ sufficiently large. Hence, there exist $\widehat{\pi}>0$ and $r^{*}$ such that $\bar{\delta}\left(0, \widehat{\pi}, r^{*}\right)<1$ for $\frac{p}{c}$ sufficiently large.

Finally, Propositions 2 and 3 show that $\delta \geq \bar{\delta}(0), \frac{p}{c}>1$, and $\epsilon(0) \geq \frac{\frac{\pi p}{1+r}}{\frac{\pi p}{1+r}+(1-\pi) \frac{\delta p}{1+r}-c}$ are sufficient conditions for the zero interest rate to be a strict optimal trade-credit rate, regardless 
of the type of the firm. Hence, if we restrict attention to equilibria in which the supplier extends trade credit to both types of firms, then $\delta \geq \bar{\delta}(0), \frac{p}{c}>1$, and $\epsilon(0) \geq \frac{\frac{\pi p}{1+r}}{\frac{\pi p}{1+r}+(1-\pi) \frac{\delta p}{1+r}-c}$ imply that the equilibrium at the zero interest rate is unique.

Proof of Proposition 6: In Proposition 5, the equilibrium with invariance at a zero interest rate obtains if the supplier's advantage in default satisfies $\delta \geq \frac{c}{p}\left(\frac{1+r}{1-\pi}\right)\left(\frac{I(0)-I\left(r_{B}\right)}{I(0)}\right)+\frac{(1+r) I\left(r_{B}\right)-\pi I(0)}{(1-\pi) I(0)}$ with $\frac{p}{c}>1$. Clearly, the restriction on $\delta$ is irrelevant if $\frac{c}{p}\left(\frac{1+r}{1-\pi}\right)\left(\frac{I(0)-I\left(r_{B}\right)}{I(0)}\right)+\frac{(1+r) I\left(r_{B}\right)-\pi I(0)}{(1-\pi) I(0)} \leq 0$ with $\frac{p}{c}>1$. To show $\delta$ may indeed be irrelevant, consider the inequality $\frac{(1+r) I\left(r_{B}\right)-\pi I(0)}{(1-\pi) I(0)} \leq 0$, or equivalently,

$$
(1+r) \frac{I\left((1+r)(f+(1+f) \pi)^{-1}\right)}{I(0)} \leq \pi .
$$

By the concavity of $I($.$) , any x \geq 0$ implies that $I(x) \leq I(0)+I^{\prime}(0) x$, which, at $x=(1+$ $r)(f+(1+f) \pi)^{-1}$ implies equation (24) if $\frac{1+r}{\pi} \leq \frac{1}{1-\epsilon(0)(1+r)(f+(1+f) \pi)^{-1}}$. This latter inequality is equivalent to $\epsilon(0) \geq\left(1-\frac{\pi}{1+r}\right) \frac{f+(1+f) \pi}{1+r-f-(1+f) \pi}$. Hence, $\epsilon(0)>\left(1-\frac{\pi}{1+r}\right) \frac{f+(1+f) \pi}{1+r-f-(1+f) \pi}$ implies that, for $\frac{p}{c}$ sufficiently large, $\frac{c}{p}\left(\frac{1+r}{1-\pi}\right)\left(\frac{I(0)-I\left(r_{B}\right)}{I(0)}\right)+\frac{(1+r) I\left(r_{B}\right)-\pi I(0)}{(1-\pi) I(0)} \leq 0$, as we wanted to prove. 


\section{REFERENCES}

Biais, Bruno and Christian Gollier, 1997, Trade Credit and Credit Rationing, Review of Financial Studies 10, 903-937.

Brennan, Michael J., Vojislav Maksimovic and Josef Zechner, 1988, Vendor Finance, Journal of Finance 43, 1127-1141

Burkart, Mike and Tore Ellingsen, 2002, In-Kind Finance, Working paper, Stockholm School of Economics.

Cuñat, Vicente, 2002, Trade Credit: Suppliers as Debt Collectors and Insurance Providers, Working paper, Universitat Pompeu Fabra.

Elliehausen, Gregory E. and John D. Wolken, 1993, The Demand for Trade Credit: An Investigation of Motives for Trade Credit Use by Small Business, Federal Reserve Bulletin.

Felli, Leonardo and Christopher Harris, 1996, Learning, Wage Dynamics, and Firm-Specific Human Capital, Journal of Political Economy 104, 838-868.

Frank, Murray and Vojislav Maksimovic, 1998, Trade Credit, Collateral, and Adverse Selection, Working paper, University of Maryland.

Mian, Shehzad L. and Clifford W. Smith, JR., 1992, Accounts Receivables Management Policy: Theory and Evidence, Journal of Finance 47, 169-200.

Ng, K. Chee, Janet K. Smith, and Richard L. Smith, 1999, Evidence on the Determinants of Credit Terms Used in Interfirm Trade, Journal of Finance 54, 1109-1129.

Petersen, Mitchell A. and Raghuram Rajan, 1994, The Benefits of Lending Relationships: Evidence from Small Business Data, Journal of Finance 49, 3-37.

ships, Quarterly Journal of Economics 60, 407-444. 
10, 661-691.

Rajan, Raghuram and Luigi Zingales, 1995, What Do We Know About Capital Structure? Some Evidence from International Data, Journal of Finance 50, 1421-1460.

Schwartz, Robert A. and David K. Whitcomb, 1997, The Trade Credit Decision, in J. Bicksler (ed.) Handbook of Financial Economics, North-Holland, Amsterdam.

Smith, Janet, 1987, Trade Credit and Informational Asymmetry, Journal of Finance 42, 863869.

Wilner, Benjamin, 2000, The Exploitation of Relationships in Financial Distress: The Case of Trade Credit, Journal of Finance 55, 153-178. 


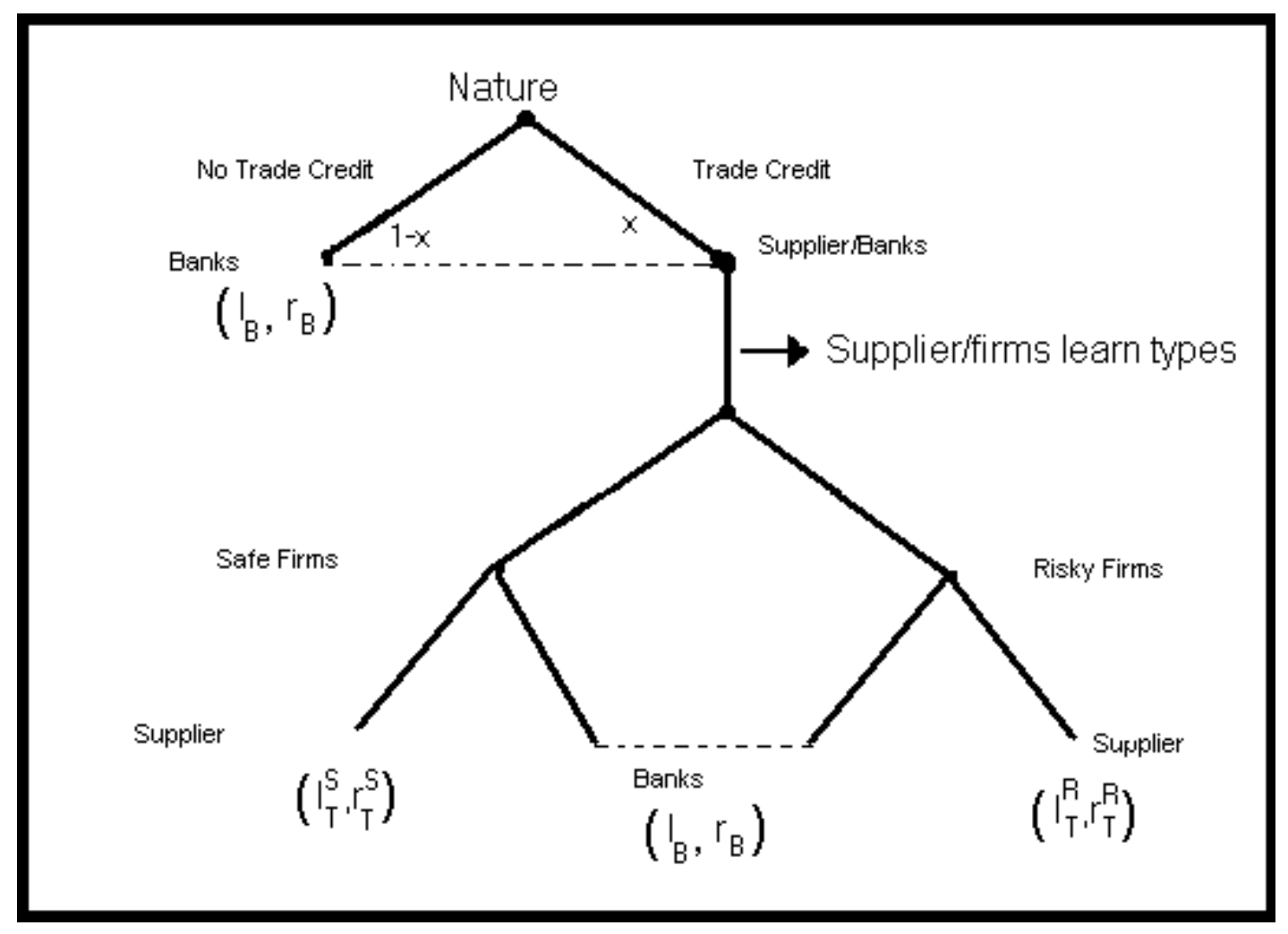

Figure 1: Game in the extensive form 